\title{
A New Sentiment Index for the Islamic Stock Market
}

\author{
Muhammad Asif Khan ${ }^{1}$ \\ Rubi Ahmad ${ }^{1}$ \\ Anna Azmi ${ }^{1}$ \\ Muhammad Akbar²
}

\section{Abstract}

This study attempts to examine the predictability of Google search volume (GSV) and to construct an appropriate investor sentiment index for Islamic stock markets for seven United States (US) Islamic stock indices. Using principal component analysis, we construct an appropriate investor sentiment index for Islamic stock markets that depicts more persistent and higher $R$-squared values for all these seven US Islamic stocks indices compared to the original Financial and Economic Attitudes Revealed by Search (FEARS) sentiment index of Da, Engelberg, and Gao (2015). The observed results can be attributed to the construction of our investor sentiment index as we have included keywords active in the Islamic stock markets. The findings of this study provide strong predictability evidence for our new sentiment index in the Islamic stock markets.

Keywords: Google Search Volume, Islamic Stock Market Return Volatility, FEARS Keywords, New Sentiment Index

\footnotetext{
${ }^{1}$ Faculty of Business and Accountancy, University of Malaya, Kuala Lumpur, Malaysia

${ }^{2}$ Birmingham City Business School, Birmingham City University, Birmingham, United Kingdom
} 


\section{Introduction}

Academic research points to significant differences between Islamic and non-Islamic financial assets as the former are filtered according to ethical standards set by Sharia (Aloui, Hkiri, Lau, \& Yarovaya, 2016; Narayan \& Bannigidadmath, 2017; Narayan \& Phan, 2017). Theoretically, a stock is considered to be Sharia compliant once it meets both qualitative and quantitative Sharia screening criteria. Islamic stocks exclude stocks in businesses associated with alcohol and pork (qualitative screening $^{3}$ ) and those that exceed the threshold for solvency-related measures (quantitative screening ${ }^{4}$ ). This conservative behavior toward leverage and the strict Shariacompliant screening process reveal empirical differences in returns and volatility of Islamic stocks in terms of market conditions, risk factors, and investor sentiment. For example, Islamic stocks behave differently in bearish and bullish market conditions due to the prohibition on speculation and strict leverage ratios (Hammoudeh, Mensi, Reboredo, \& Nguyen, 2014; Razak, Ismail, \& Aridi, 2016). According to Merdad, Hassan, and Hippler (2015), Islamic stocks have an additional Islamic risk factor that is negatively related to returns and hence investor sentiment has a more distinct effect on Islamic stock returns and volatility than on their counterparts (Aloui et al., 2016; Narayan \& Bannigidadmath, 2017).

Google search volume (GSV), a proxy for investor attention/sentiment, has been used in the literature as a predictor of stock prices (both returns and volatility). For instance, Da, Engelberg, and Gao (2011) use GSV in the capital market as a proxy for investors' attention and report it as a better predictor for stock prices. Concurrently, Joseph, Wintoki, and Zhang (2011) report Google

\footnotetext{
3 The Dow Jones system, for example, identifies the following business activities as inappropriate for Islamic investments: Tobacco, Life Insurance, Restaurants \& Bars, Broadcasting \& Entertainment, Media Agencies, Food Products, Recreational Services, Defense, Distillers \& Vintners, Mortgage Finance, Food Retailers \& Wholesalers, Consumer Finance, Recreational Products, Specialty Finance, Brewers, Gambling, Hotels, Banks, Full Line Insurance, Insurance Brokers, Property \&amp; Casualty Insurance, Reinsurance and Investment Services.

4 Total debt to market capitalization, accounts receivables to market capitalization, and cash and interest-bearing securities to market capitalization should all be $33 \%$ of the 24 -month average trailing market capitalization (Narayan et al., 2016).
} 
search intensity as a direct proxy for investor sentiment that can explain and predict the sensitivity of stocks' abnormal returns. Moreover, Zhang, Li, Su, and Zhang (2014) report that online search intensity as a proxy for investor sentiment has a higher explanatory and predictive ability than traditional proxies (Ye \& Li, 2017). Similar findings are reported by Dimpfl and Jank (2016), who investigate GSV and US stock market volatility.

GSV signifies investor sentiment by revealing information that can best represent investors' attitude toward the market at the time. In fact, investors are heterogeneous by nature, which may lead to bias toward extrapolative expectations and drive investors' demand for assets based on information about future cash flows other than their fundamental values. Most studies have used the name or ticker symbol of the securities in GSV to determine investor attention/sentiment. For instance, Vlastakis and Markellos (2012) investigate the top 30 firms by their tickers and report a positive significant correlation between Google search intensity and stock market volatility. They argue that search intensity increases with the level of investors' risk aversion.

GSV (investor sentiment) predictability has been tested for different factors (e.g., return, volatility, liquidity, earnings announcement, initial public offering) in different conventional markets (i.e., stock, bond, energy, commodity, and foreign exchange) and reported as a timely fashion measure for market predictability. ${ }^{5}$ Since Islamic stocks' return and volatility differ from those of conventional stocks (Razak et al., 2016), it is important to evaluate the efficacy of sentimentinduced keywords searched in Google as a predictor for the Islamic stock market. We, therefore, cover the following three objectives in this study. First, we empirically investigate the relationship between FEARS sentiment-induced keywords searched in Google and the US Islamic

\footnotetext{
${ }^{5}$ Liquidity (Bank, Larch, \& Peter, 2011; Aouodi, Arouri, \& Roubaud, 2018), Stock returns (Da et al., 2011, 2015; Joseph, Wintoki, \& Zhang, 2011), Volatility (Da et al., 2015; Hamid \& Heiden, 2015), Earnings Announcement (Drake, Roulstone, \& Thornock, 2012; Wang, Choe, \& Siraj, 2018), IPO (Da et al., 2011; Zhao, Xiong, \& Shen, 2018).
} 
stock market return volatility. Second, we analyze the sentiment-induced keywords (FEARS) predictability in US Islamic stocks' market return volatility beyond the generalized autoregressive conditional heteroskedasticity $(\mathrm{GARCH})(1,1)$ model. Third, we construct a direct measure of the investor sentiment index that can better predict Islamic stocks' market return volatlity.

The novelty of our study comes from filling the gap in the GSV literature by examining its predictive ability for Islamic stocks. We have looked at seven US Islamic stocks indices: Dow Jones US Islamic Index, Dow Jones US Islamic Small Cap, Dow Jones US Islamic Medium Cap, Dow Jones US Islamic Large Cap, FTSE Shariah US, MSCI Shariah USA, and S\&P 500 Shariah Index. We use weekly time series data for a series of 118 FEARS sentiment-induced keywords from January 2010 through December 2017.

We contribute to the wider literature of investor sentiment (Al-Hajieh, Redhead, \& Rodgers, 2011; Baker \& Wurgler, 2006, 2007; Da et al., 2015; Ftiti \& Hadhri, 2019; Jaziri \& Abdelhedi, 2018; Perez-Liston, Huerta, \& Haq, 2016; Sibley, Wang, Xing, \& Zhang, 2016) by constructing an investor sentiment index for the Islamic stock market. Our findings reveal that our household investor sentiment index (FEARS15) has predictive ability for Islamic stocks' return volatility. We also compare our sentiment index (FEARS15) with Da et al.'s (2015) sentiment index (FEARS30) for our sample of US Islamic stock indices. By regressing both sentiment indices with conditional and unconditional volatility, we find that our sentiment index (FEARS15) posits higher and statistically significant $R$-squared values for all seven US Islamic stocks indices. Moreover, our findings suggest that FEARS15 can provide better in-sample and out-of-sample forecasts of both unconditional volatility and conditional volatility. 
The remainder of this paper is structured as follows: Section 2 reviews the literature, section 3 describes the data and empirical approach, section 4 provides the results and discussion, and section 5 presents the conclusions and limitations of the study.

\section{Literature Review}

\section{Measures of investor sentiment}

Two types of investors, informed traders and noise traders, derive stock prices in the stock market (Shleifer \& Summers, 1990). Arbitragers (informed traders) try to eradicate price dispersion and bring the price back to its "true" value. However, noise trader trades are based on pseudo-signals and other noise trading models. De Long, Shleifer, Summers, and Waldmann (1990) came up with the noise trader model and described the reasons why noise traders' risk is priced in the financial market. More specifically, noise trader theory states that noise traders act coherently on a noisy signal that may cause systematic risk in the market. If irrational investors affect asset prices, the noisy signal they act upon is sentiment and the systematic risk originated is volatility. This shows a correlation between investor sentiment and volatility. De Long et al. (1990) explained that the divergence in asset prices will revert to the asset's fundamental value, but this process takes a longer time.

Baker and Wurgler (2007) argued that the question is no longer whether sentiment affects stock prices but how to measure investor sentiment and quantify its effect. The finance literature proposes three prominent measures of investor sentiment: market-based proxies (Baker \& Wurgler, 2006, 2007), the survey approach (Brown \& Cliff, 2005; Perez-Liston et al., 2016), and search-based approach (Da et al., 2011, 2015; Joseph et al., 2011; Solanki \& Seetharam, 2018). However, researchers have criticized the market-based proxies and survey approach. For example, 
Sibley et al. (2016) argued that the market-based sentiment index (Baker \& Wurgler, 2006) is influenced more by economic variables than by investor sentiment. Similarly, Singer (2006) argued that people do not want to answer questions in a survey due to little incentive or high sensitivity.

The Google search-based approach gained increased attention in the finance literature after the foundational work of Da et al. (2011) that used search intensity as a proxy for investor attention. In the Google search intensity literature, different indicators have been used to measure sentiment, attention, and divergence of opinions. However, Da et al. (2011, 2015) and Joseph et al. (2011) used different company names and a dictionary-based approach to capture investor sentiment. The lexical category dictionary-based approach has been further divided into two prominent approaches of investor sentiment analysis. In the first approach, sentiment-induced keywords are selected from the sample text and then applied to all the text as a judgment criterion (Zhang, Fuehres, \& Gloor, 2011). In the second approach, pertinent keywords are extracted from the actual dictionary and used for the sample text (Bartov, Faurel, \& Mohanram, 2017; Da et al., 2015; Sul, Dennis, \& Yuan, 2017). Both approaches are important to measure investor sentiment and exhibit its effectiveness in the financial market. However, Sul et al. (2017) supported the actual dictionary approach as an appropriate method for internet-related investor sentiment.

\section{Investor sentiment in the Islamic stock market}

The Islamic financial system is considered an alternative investment-opportunity market for investors. Islamic finance involves the practice of investment and finance based on Sharia principles. The motives attributed to Islamic financial products are to enhance social welfare and public goods, limit social crises, curtail potential injustice, and contribute real value to the economy (Dash \& Maitra, 2018b). Contrary to the motives, in practice Sharia-compliant securities 
may be affected by market and economic factors such as macro-economic factors and investor sentiment that enable investors to earn higher than market returns.

Theoretically, sentiment and Sharia-compliant security returns (volatility) have two complementary arguments. The first is that Sharia indices have strict and active Sharia monitoring and faith-based investors. This may not allow Islamic stocks to tend toward sentiment and may avoid sentiment-induced mispricing. Second, the Sharia-screening process (both qualitative and quantitative) may lead stocks to short-selling impediments (Miller, 1977) and limit arbitrage (Shleifer \& Vishny, 1997), which may mean that Sharia stocks are influenced more by noise traders that deviate their prices from fundamentals for the long term. This complementary argument needs to be emperically tested to determine whether the Shaira active monitoring and faith-based investment are expected to have higher infulence on Islamic stock returns volatility.

In recent years, the complementary arguments related to Islamic stocks and sentiment have triggered researchers' interest in studying investor sentiment and stock returns. For instance, Narayan and Bannigidadmath (2017) used sentiment-induced keywords to examine the effect of financial news on Islamic stock returns. Their findings exhibited higher predictability for sentiment-induced keywords in Islamic stocks than non-Islamic stocks. Similarly, Trichilli, Abdelhédi, and Boujelbène (2018) examined FEARS investor sentiment predictability for Islamic stock returns in Middle East and North Africa (MENA) stock markets. They concluded that investor sentiment using search data has higher predictability in Islamic stock markets.

Little attention, however, has been paid to sentiment sensitivity and return volatility of Shariacompliant stocks (Dash \& Maitra, 2018a; Perez-Liston et al., 2016). For instance, Perez-Liston et al. (2016) investigated the effect of investor sentiment on Islamic stock returns and volatility and found that higher sentiment in the contemporaneous period leads to lower conditional volatility in 
the subsequent period. Similarly, Wasiuzzaman (2018) studied the effect of Hajj pilgrimage sentiment on the return volatility of the Suadi stock market. His study revealed a significant negative relationship between sentiment and return volatility. Unlike the previous studies, our paper focuses on the relationship between investor sentiment and Islamic stock return volatility using a new investor sentiment measure from GSV. Earlier studies focused on the sentiment index that was constructed for the conventional stock market. For instance, Narayan and Bannigidadmath (2017) used sentiment-induced keywords found in the financial news about financial markets. In contrast, we used a new sentiment index consisting of keyword combinations that are active in the Islamic stock market.

\section{Data and Empirical Methods}

This section presents the data and empirical methods of our study. First, we discuss the description, selection of market, and procedure of gathering GSV data. Second, we explain the methods and procedures used in the empirical analysis.

\section{Google search volume}

We used GSV as a measure of household investor interest. The search volume intensity (SVI) data can be retrieved from either Baidu (China) or Google Trends. GSV is a free resource for search volume for the company name, ticker, or other sentiment keywords available, both global and country-specific, at different frequencies (daily, weekly, monthly) from January 2004 onward. The normalized GSV data are available from 0-100 search frequencies for specific words and for a specified period. Relative GSV data are also available and are measured as the number of searches

for a keyword divided by the total number of searches for all the keywords for a period. Relative GSV eradicates the bias of variation in GSV due to an increase in the number of users over time 
(Adachi, Masuda, \& Takeda, 2017). Given the nature of our study, we retrieved data for the US region following Preis, Moat, and Stanley (2013) as GSV data for the US have better predictability for the stock market than the global market.

Frequency bias might exist due to the different number of frequencies between GSV (seven days) and trading days (five days) for each week. To avoid this potential bias, we collected daily data (available only for each keyword for a 90-day time series) for a list of 118 "primitive keywords" from Da et al.'s (2015) FEARS words dictionary from January 2010 through December 2017. We then aggregated the daily data on each keyword from the FEARS words dictionary for each week over the full sample period and matched them against the Islamic indices' return (volatility).

\section{Islamic stock index volatility}

According to Schröder (2007), index level data tend to perform better than portfolio construction or fund data (Dash \& Maitra, 2018b). Therefore, we collected daily Islamic stock index prices for seven indices: Dow Jones US Islamic market, Dow Jones US Islamic market (large, medium, and small capitalization), S\&P 500 Sharia, FTSE Islamic US market, and MSCI Islamic US market. Data (index values) on all these indices were retrieved from DataStream from January 2010 through December 2017. The choice of the sample period was driven by three factors. First, the US Islamic stocks indices used in the study were launched on different dates where the latest data are available from April 2008. Second, the data available on Google Trends are more reliable after 2008 (Bijl, Kringhaug, Molnár, \& Sandvik, 2016). Third, we did not include 2008-2009 in our sample as these years represented the financial crisis and may have adversely affected the empirical results and findings of the study. 
We computed daily rates of return for the indices by taking the natural log of the ratio between daily closing and opening index values as:

$r_{-} t=\ln \left(p_{-} t / p_{-}(t-1)\right)$

where $r$ and $p$ illustrate return and price of the index on day $t$. Volatility was measured as the standard deviation of daily returns for each week (for five trading days) as:

$V_{t}=\sqrt{\frac{1}{n_{t}-1} \sum_{d \epsilon t}\left(r_{d}-\bar{r}\right)^{2}}$

where $V_{t} V, n_{t}$, and $r^{-}$exhibit weekly realized return volatility calculated from a daily return, number of days per week (five), and an average of the daily index returns, respectively.

\section{INSERT TABLE 1 HERE}

\section{Empirical approach and results interpretations}

We follow Afkhami, Cormack, and Ghoddusi (2017) to analyze the predictive power of FEARS keywords in the US Islamic stock market. However, our approach differs from theirs in three ways. First, we matched the real dates for GSV and trading days (five days a week). Second, in the ordinary least squares (OLS) filtration process, we only considered those keywords and/or combinations that had significant $F$-statistics at $1 \%$ with keywords significant at $5 \%$ to get the most suitable sum of predictive FEARS sentiment keywords for Islamic stock index return volatility. Third, using the principal components analysis (PCA) approach, we constructed a new sentiment index for the Islamic stock market.

The empirical analyses of the study involved three steps. First, empirical analyses were conducted to select keywords that Granger-caused price volatility and had cumulative predictive ability beyond the GARCH $(1,1)$ model. Then, we analyzed different combinations of keywords that 
have significant and incremental power to explain Islamic stock return volatility. In the third step, we constructed a new investor sentiment index from the combination of FEARS keywords and tested its predictive ability for in-sample and out-of-sample Islamic stock return volatility.

\section{FEARS sentiment keywords for Islamic stock return volatility}

Da et al. (2015) used 118 primitive keywords to construct the FEARS sentiment index comprising 30 keywords and analyzed the predictability of conventional stock market returns and volatility. In contrast, we examined the same 118 primitive keywords of Da et al. (2015) for Islamic stock market return volatility to construct a new sentiment index for the Islamic stock market. We applied the augmented Dickey-Fuller (ADF) test to the data series of all the keywords and Islamic stock index returns to assess the stationarity of each data series. Though not reported here, the ADF test results suggested rejection of the null hypothesis of a unit root in most cases. To investigate the FEARS keywords predictability of Islamic stock return volatility, we first conducted a Granger causality test on weekly data for each of the seven US Islamic stocks indices and the 118 primitive FEARS keywords one by one. Specifically, we used the vector autoregressive (VAR) model in equation 3 to test for Granger causality (Granger, 1969).

$V_{t}=c+\sum_{i=1}^{p} \beta_{1 i} V_{t-i}+\sum_{j=1}^{q} \beta_{2 j} G_{t-j}+\epsilon_{t}$

where $V_{t}$ and $G_{t}$ denote week $t$ data for both volatility and search volume FEARS keywords at $p$ and $q$ lag orders, respectively; $\beta \_1$ and $\beta \_2$ are the coefficients for volatility and search volume. We employ the $F$-test to test (at lag order 2 ) the null hypothesis that $G_{-} t$ does not Granger-cause $V_{-} t$; that is,

$\mathrm{H}_{0}: \beta \_2 j=0 j=1,2 \ldots \ldots q$ 
Table 2 reports the $p$-values of all those FEARS sentiment keywords that are significant at $10 \%$ for the null hypothesis (i.e., GSV keyword does not Ganger-cause Islamic stock index volatility). This step enables us to keep only those keywords that illustrate significance for volatility in the seven Islamic stocks indices. The finding of Granger causality in Table 2 reveals different series of keywords for each Islamic stock index volatility. Out of the seven Islamic stock indices, the list of keywords for the Dow Jones Islamic US Mid Cap-Price index and MSCI AC Americas IS US Price index carry a larger number of keywords, 34 and 29 keywords, respectively. However, the interesting fact is the consistency among 15 keywords common across all seven Islamic stock index volatilities. Vozlyublennaia (2014) and Dimpfl and Jank (2016) also used Granger causality tests to examine the relation between search keywords and stock market volatility and reported that search keywords exhibit information about future stock return volatility. ${ }^{6}$

\section{INSERT TABLE 2 HERE}

\section{Articulation of GARCH model}

In a multivariate time series, the "dimensionality curse" is problematic in the GARCH model. The reason is that parameters are called for in the conditional variance matrix. Dimensionality can be avoided either by a reduction in parameters (Lanne \& Saikkonen, 2007) or alternative estimation criteria (Engle, Shephard, \& Sheppard, 2009). Engle and Sheppard (2001) proposed two steps to prevent the high-dimensional input vector problem. In the first step, the univariate GARCH model is estimated for every single individual series and, in the next step, standardized residuals are used for the estimation of dynamic correlation (see Francq \& Zakoïan, 2015). As compared to adding a

\footnotetext{
${ }^{6}$ Other studies include the oil market (Li, Ma, Wang, \& Zhang, 2015), tourism market (Siliverstovs \& Wochner, 2018; Sun et al., 2019), and stock market (Vlastakis \& Markellos, 2012).
} 
predictor in the GARCH $(1,1)$ model approach, Sucarrat and Escribano (2012) stated that this alternative approach avoids the problems caused by high-dimensionality input vectors and allows for testing hypotheses through the ordinary method.

For all seven Islamic stock indices, we followed the GARCH framework of Engle (1982) and Bollerslev (1986) to model the log of weekly returns. The returns' conditional variance depends solely on the lagged squared residuals of the returns process. At week $(t) \alpha_{t}=r_{t}-\mu_{t}$ is the return innovation that can be modeled as the following $\operatorname{GARCH}(1,1)$ process:

$a_{t}=\sqrt{h_{t}} \epsilon_{t}$

where $h_{-} t$ denotes the process

$h_{t}=\omega+\gamma a_{t-1}^{2}+\beta h_{t-1}$

where $\omega>0, \gamma \geq 0, \beta \geq 0$, and $(\gamma+\beta)<1$. The last restraint is to check the assumption of stationarity for GARCH that refers to how swiftly the variance returns to the long-term mean (i.e., the speed of mean reversion). Moreover, $a_{t}$ implies the unconditional variance at the limit; nonetheless, conditional variance $\left(h_{t}\right)$ develops over time. The error term $\epsilon_{t}$ in equation 5 is random (i.e., $i i d$ ), with variance 1 and mean 0 . We estimated equation 6 for all seven Islamic market indices using the maximum likelihood method with $t$-distributed errors considering excess kurtosis in stock returns. The estimated parameters from these estimations for each index are presented in Table 3. The values of $\gamma$ and $\beta$ are highly significant at the $1 \%$ level and suggest consistency in price volatility and slow mean reversion for all seven indices (see Table 3).

\section{INSERT TABLE 3 HERE}




\section{GSV predictive power beyond GARCH}

From the GARCH $(1,1)$ model, the vector of conditional variances, $h_{t}$, for each stock index was extracted. The lagged GSV for each FEARS searched keyword along with lagged conditional variance $\left(h_{-}(t-1)\right)$ were used as the explanatory variable in the OLS regressions. This is given in equation 7 as:

$\ln \left(a_{t}^{2}\right)=\beta_{0}+\beta_{1} h_{t-1}+k_{1} G_{t-1}+Z_{t}$

where $\ln \left(a_{t}^{2}\right)$ symbolizes "shock" (i.e., the squared residuals from the mean equation); $\beta_{1}$ and $k_{1}$ represent the one-week lagged values of parameter estimates of $\mathrm{GARCH}(1,1)$ conditional variance and search volume predictors, respectively, and $G_{t-1}$ is the lag value for each FEARS searched keyword's GSV. In equation 7, $\beta_{0}$ and $Z_{t}$ denote intercept and error term, respectively. We used Newey and West's (1986) standard errors to deal with any autocorrelation and heteroskedasticity in the residual up to 14 lags estimated for significance tests. Next, for each FEARS keyword, the null hypothesis that the FEARS keyword's GSV does not predict return volatility beyond GARCH (i.e., $k_{1}=0$ ) is tested via a $t$-test and $F$-test.

The results for the one-factor keywords that rejected the null hypothesis (searched keyword's GSV has no predictive ability for volatility beyond the GARCH model) are reported in Appendix A2. The results reveal significant sentiment-induced keywords and suggest that a series of searched keywords' GSVs has the ability to predict the conditional volatility of Islamic stock indices beyond GARH, as indicated by statistically significant $t$-statistics and $F$-statistics. Most FEARS keywords' GSVs negatively relate to Islamic stock indices' conditional volatility (Appendix A2). The keywords searched in the week negatively affect subsequent volatility in the Islamic market indices. This finding is consistent with Perez-Liston et al. (2016) and Wasiuzzaman (2018), who 
investigated the effect of investor sentiment on Islamic stock volatility and found that higher sentiment in the contemporaneous period leads to lower conditional volatility in the subsequent period. Loughran and MacDonald (2011) argued that investors focus only on negative keywords. Da et al. (2015) and Solanki and Seetharam (2018) also reported similar findings in their studies of the relationship between search keywords and volatility for conventional stocks.

\section{Enhancing predictive power by increasing searched keywords}

We extended our model by including more than one FEARS keyword to assess the enhancement in the keyword's predictive power for conditional volatility beyond the model in equation 7. First, we included one more significant searched keyword to equation 7 to obtain:

$\ln \left(a_{t}^{2}\right)=\beta_{0}+\beta_{1} h_{t-1}+k_{1} G_{1, t-1}+k_{2} G_{2, t-1}+Z_{t}$

where parameter $k_{2}$ estimates the marginal effect of the GSV of the second keyword, $G_{-}(2$,$) . We$ tested the null hypothesis $k_{2}=0$ (i.e., keeping the GSV of the first searched keyword $G_{1}$ constant) and found that an addition to GSV of one more searched keyword $G_{2}$ does not enhance GSV's predictive power. Only those keywords represented in the tables (see Appendix A3) illustrate that the GSV of FEARS keywords enhances the predictive power at the 5\% level of significance using $F$-statistics.

The results for the combination of two factors (keywords) are reported in Appendix A3 and show an increase in predictive power as compared to the one-factor searched keyword in Appendix A2. This increase in predictability suggests that the combinations of search keywords can enhance the explanatory power and provide more information about future volatility of Islamic stock returns. The signs of the coefficients on $k_{1}$ and $k_{2}$ suggest a negative relation between the searched keywords' GSVs and the conditional volatility of Islamic stock indices (Appendix A3). 
Following the same filtration process, we then included one additional searched keyword to the estimation specification to get the model in equation 9:

$\ln \left(a_{t}^{2}\right)=\beta_{0}+\beta_{1} h_{t-1}+k_{1} G_{1, t-1}+k_{2} G_{2, t-1}+k_{3} G_{3, t-1}+Z_{t}$

where parameter $k_{3}$ estimates the marginal effect of the GSV of the third searched keyword $G_{3}$. In equation 9, we test the null hypothesis that $k_{3}=0$ (i.e., keeping the GSV of the first and second searched keywords); an addition of GSV of one more searched keyword $G_{3}$ does not enhance GSV's predictive power.

The combinations of three search keywords with higher adjusted $R$-squared values than the two search keywords combinations are presented in Appendix A4. We observe from Appendix A4 that the marginal effect from the third search keyword is negative and consistent with existing research. Like the earlier steps, we expanded our analysis to four keywords combinations. The results, though not reported here, suggest no statistically significant combinations of four or more search keywords for US Islamic stock indices given our criteria that required that $R$-squared must increase in addition to the statistical significance of the coefficient $k_{n}$.

Subsequently we applied the PCA approach to reduce input vectors' dimensionality and construct an index from the primitive keywords to better explain the volatility of US Islamic stock indices compared to the original FEARS index developed by Da et al. (2015).

\section{Principle component analysis}

To construct our own investor sentiment index from the search keywords, we used PCA on the search keywords that were found statistically significant from our Granger causality tests and the three keyword combinations (Appendix A4). The PCA approach can translate high dimensional input vectors into low dimensionality non-correlated vectors (for details, see Cho, Lee, Choi, Lee, 
\& Lee, 2005). In our study, the principal components are the linear combinations of each search keyword and the information contained in each principal component is calculated by its variance. All principal components were ranked by descending value of their variance. So, the first principal component is more informative while the last is least informative. ${ }^{7}$ For consistency reasons, we run the PCA test on the common search keywords (15 search keywords) found from the Granger causality tests for all seven US Islamic stock indices. In addition, we analyzed different series of keywords filtered from the three-factor (three search keywords) combinations for each Islamic stock index.

We constructed FEARS sentiment indices using the PCA approach on the search keywords series mentioned in Appendix A5. Initially, we selected the 15 common keywords (FEARS15) that passed the Granger causality filtration process for all seven Islamic stock indices' return volatility as well as the three search keyword combinations (FEARSd1-7) that exhibited higher adjusted $R$ squared values for the respective Islamic stock index conditional volatility. For comparison, we also picked the original FEARS index (FEARS30) constructed for the conventional stock market by Da et al. (2015). This approach enabled us to construct a sentiment index and examine its predictability for US Islamic stock indices.

\section{Investor sentiment index and Islamic stock return volatility}

To examine the predictive power of our investor sentiment indices constructed from PCA and the FEARS 30, we estimated the following two models (one each for unconditional and conditional volatility) for the seven US Islamic stock indices individually.

$U V_{t, j}=\beta_{0}+\beta_{1} F E A R S_{t, k}+\varepsilon_{t}$

\footnotetext{
${ }^{7}$ For further detail, see Yao, Zhang, and Ma (2017).
} 
$C V_{t, j}=\beta_{0}+\beta_{1} F E A R S_{t, k}+\varepsilon_{t}$

where $U V$ and $C V$ are the unconditional and conditional volatilities of Islamic stock index $j$ at time $t$, FEARS is the measure of sentiment index $k$ at time $t$ constructed using PCA, and $\varepsilon$ is the random error term. We also regressed both unconditional volatility and conditional volatility of each index on first, second, third, and fourth lags of both FEARS15 and FEARS30 separately to assess the predictive ability of each investor sentiment index. For a robustness check, we further divided our sample into two sub-samples (i.e., January 2010 - December 2013 and January 2014 - December 2017) and estimated the regressions for all seven US Islamic stock indices separately over each sub-sample. We also provided in-sample and out-of-sample analyses for our FEARS15 index (given the empirical results that follow, it outperforms the FEARS30 index).

We regressed our investor sentiment index constructed from PCA (i.e., FEARS15 and FEARS30) with unconditional volatility and conditional volatility of each of the seven Islamic stock indices. The FEARS15 sentiment index has a negative coefficient that is statistically significant at the $1 \%$ level for all Islamic stock indices' contemporaneous unconditional volatility and conditional volatility (Table 4). Interestingly, FEARS15 has highly significant negative coefficients and relatively higher adjusted $R$-squares than FEARS30 in all the cases. Furthermore, we observe that the $R$-squared values are generally increasing and higher at lag 4 in the case of unconditional volatility. For example, the $R$-squared value increases from $5.3 \%$ at time $t$ to $7.6 \%$ at time $t$-4 (lag 4) for the unconditional volatility of the first Islamic index, that is, $d 1 d$ (Table 4). However, there 
is no discernable trend in the observed R-squared values for all the Islamic indices in the case of conditional volatility with FEARS15. Our findings are consistent with Perez-Liston et al. (2016), who also reported a negative relationship between investor sentiment and subsequent Islamic stock market volatility.

\section{INSERT TABLE 4 HERE}

In the case of the FEARS30 sentiment index (Da et al.. 2015), the estimated coefficients are positive (except $d 6 d$ at lag 3 and lag 4 ) but statistically insignificant (except that $d 4 d$ is significant at 5\%) in the case of both unconditional and conditional volatility (Table 4). These results suggest that the FEARS30 sentiment index fails to predict the return volatility of our sample US Islamic stock indices. Narayan and Bannigidadmath (2017) reported a similar result and argued that the same sentiment-induced search keywords in the US stock market can only predict a non-Islamic stock market. This may be because the combinations in search keyword selection are effective for non-Islamic stocks but not for Islamic stocks as a consequence of the differences between the two types of stock.

These results unfold the interesting insight that different sentiment-induced search keyword combinations may predict investor sentiment in Islamic and non-Islamic stock markets. For example, in Da et al.'s (2015) study, the keyword "recession" has the second highest $t$-statistic value of -5.60 while it is not selected for inclusion in our new investor sentiment index (i.e., FEARS15). Razak et al. (2016) also argued that Islamic stock markets are more stable in recession than normal economic conditions and hence the measures of investor sentiment should vary across Islamic and non-Islamic stock markets. 
For a robustness check, we divided our sample into two sub-samples: January 2010 - December 2013 and January 2014 - December 2017. We followed the same procedure as followed for the full sample case to estimate equation 10 and equation 11 over both the sub-sample periods. The results of the first sub-sample (i.e., January 2010 to December 2013) are provided in Appendix A6. Though the results are qualitatively robust to those reported for the full sample in Table 4, the relatively lower $R$-squared values exhibit relatively lower predictability in most instances. This is, however, not the case over the second sub-sample (i.e., January 2014 to December 2017); see Appendix A7. The FEARS15 investor sentiment index illustrates strong and incremental explanatory power from time $t$ (i.e., lag 0 ) of $6.7 \%$ to time $t-4$ (i.e., lag 4 ) of $9.7 \%$. More interestingly, the FEARS30 also posits statistically significant positive coefficients at time lag 0 to time lag 2 for Islamic stock indices' unconditional and conditional volatility. Hence, the results of the sub-sample confirm our findings from the full sample analysis, but suggest that that there are time variations where the relationship is stronger over the second sub-sample period. These outcomes highlight investor confidence in the emergence and use of the GSV of sentiment-induced search keywords in investing in stocks.

To assess the in-sample and out-of-sample forecasting ability of our investor sentiment index (i.e., FEARS15), we forecast both the unconditional and conditional volatility of the US Islamic stock indices using FEARS15 as well as FEARS30 (Da et al., 2015). As observed, the $R$-squared was highest at lag 4 of the FEARS for both unconditional and conditional volatility; we used lag 4 of 
FEARS15 and FEARS30 for forecasting in each case separately. ${ }^{8}$ For the out-of-sample forecasting of unconditional and conditional volatility, we used the first five years (2010 through 2014) to estimate the model to forecast the last three years (2015 through 2017). ${ }^{9}$ We compared the forecast evaluations from both FEARS15 and FEARS30 for both unconditional and conditional volatility to determine if forecasts with FEARS15 outperform forecasts with FEARS30. Summaries of our evaluation of these forecasts are provided in Table 5. Overall, the forecast evaluation measures suggest that forecasts from FEARS15 outperform those from FEARS30 in most instances. For example, the root mean square error of the FEARS15 forecast is lower than that of the FEARS30 forecast in all the cases for both unconditional and conditional volatility. Similarly, Theil's inequality coefficient is lower for the FEARS15 forecast than the FEARS30 forecast in including all in-sample and out-of-sample instances. The findings from the forecast evaluations do not change materially between in-sample and out-of-sample instances. Therefore, there is strong empirical support for our investor sentiment index (i.e., FEARS15) as a tool to measure investor sentiment using GSV for Islamic stocks. Our empirical evidence also suggests that Da et al.'s (2015) FEARS30 sentiment index may only be suitable for non-Islamic US stocks. Furthermore, our findings suggest that FEARS15 can provide better in-sample and out-of-sample forecasts of both unconditional volatility and conditional volatility.

\section{INSERT TABLE 5 HERE}

\footnotetext{
8 Though not reported here, the results from the forecast evaluation did not differ qualitatively when lag $1,2,3$, and 4 of the FEARS15 and FEARS30 were used to forecast both unconditional and conditional volatility.

${ }^{9}$ All the forecast estimates were static.
} 


\section{Conclusion}

We examined the predictability of seven US Islamic stock indices' return volatility using the GSV of sentiment search keywords with the objective of constructing an appropriate new investor sentiment index. Earlier studies, such as Joseph et al. (2011), focused on investor sentiment using the GSV of the name or ticker of the company. However, the question is whether the name or ticker of the company can truly reflect investor sentiment. We, therefore, used the GSVs of 118 sentiment-induced keywords as identified in Da et al. (2015).

To overcome any bias that may be due to the difference in trading days and GSV frequency, we matched the daily dates to convert data from daily into weekly occurrences. The GSVs of 118 sentiment-induced search keywords were passed through a multistage filtration process including Granger causality tests to come up with a list of keywords that were considered to be better predictors of Islamic stock return volatility. We estimated weekly unconditional volatility of the Islamic stock returns using daily returns and the weekly conditional volatility from the GARCH $(1,1)$ model. To construct our investor sentiment index (i.e., FEARS15), we applied PCA to select the search keywords to include in our sentiment index. The empirical analysis provided strong evidence in support of our FEARS sentiment index as a predictor of both unconditional and conditional volatility of Islamic stock return volatility. The findings suggest a negative and statistically significant relationship between FEARS15 and volatility. However, our results do not support Da et al.'s (2015) FEARS30 as a predictor of the volatility in Islamic stock markets. Our investor sentiment index (i.e., FEARS15) outperformed FEARS30 in both in-sample and out-ofsample forecast accuracy. 
This research explores a new dimension of GSV as a direct measure of investor sentiment in Islamic stock markets. This is more useful for individual investors as they generally have limited access to paid information resources. The ultimate benefit of GSV is its free availability of highfrequency time series data for both the global market and country-specific markets. To predict market sentiment, individual and institutional investors can use our measure of investor sentiment to design their trading and risk management strategies in Islamic stock markets. However, we suggest that future research put the FEARS15 investor sentiment index to empirical tests across different markets beyond the US. It will also be interesting and useful to examine the time varying co-movement between investor sentiment and Islamic stock markets.

\section{References}

Adachi, Y., Masuda, M., \& Takeda, F. (2017). Google search intensity and its relationship to the returns and liquidity of Japanese startup stocks. Pacific-Basin Finance Journal, 46, 243-257.

Afkhami, M., Cormack, L., \& Ghoddusi, H. (2017). Google search keywords that best predict energy price volatility. Energy Economics, 67, 17-27.

Al-Hajieh, H., Redhead, K., \& Rodgers, T. (2011). Investor sentiment and calendar anomaly effects: A case study of the impact of Ramadan on Islamic Middle Eastern markets. Research in International Business Finance, 25(3), 345-356.

Aloui, C., Hkiri, B., Lau, C. K. M., \& Yarovaya, L. (2016). Investors' sentiment and US Islamic and conventional indexes nexus: A time-frequency analysis. Finance Research Letters, 19, 54-59.

Baker, M., \& Wurgler, J. (2006). Investor sentiment and the cross-section of stock returns. The Journal of Finance, 61(4), 1645-1680.

Baker, M., \& Wurgler, J. (2007). Investor sentiment in the stock market. Journal of Economic Perspectives, 21(2), 129-152.

Bartov, E., Faurel, L., \& Mohanram, P. S. (2017). Can Twitter help predict firm-level earnings and stock returns? The Accounting Review, 93(3), 25-57.

Bijl, L., Kringhaug, G., Molnár, P., \& Sandvik, E. (2016). Google searches and stock returns. International Review of Financial Analysis, 45, 150-156.

Bollerslev, T. (1986). Generalized autoregressive conditional heteroskedasticity. Journal of Econometrics, 31(3), 307-327.

Brown, G. W., \& Cliff, M. T. (2005). Investor sentiment and asset valuation. The Journal of Business, 78(2), 405-440.

Cho, J.-H., Lee, J.-M., Choi, S. W., Lee, D., \& Lee, I.-B. (2005). Fault identification for process monitoring using kernel principal component analysis. Chemical Engineering Science, 60(1), 279-288. 
Da, Z., Engelberg, J., \& Gao, P. (2011). In search of attention. The Journal of Finance, 66(5), 1461-1499.

Da, Z., Engelberg, J., \& Gao, P. (2015). The Sum of All FEARS Investor Sentiment and Asset Prices. The Review of Financial Studies, 1-32.

Dash, S. R., \& Maitra, D. (2018a). Does sentiment matter for stock returns? Evidence from Indian stock market using wavelet approach. Finance Research Letters, 26, 32-39.

Dash, S. R., \& Maitra, D. (2018b). Does Shariah index hedge against sentiment risk? Evidence from Indian stock market using time-frequency domain approach. Journal of Behavioral Experimental Finance.

De Long, J. B., Shleifer, A., Summers, L. H., \& Waldmann, R. J. (1990). Noise trader risk in financial markets. Journal of Political Economy, 98(4), 703-738.

Dimpfl, T., \& Jank, S. (2016). Can internet search queries help to predict stock market volatility? European Financial Management, 22(2), 171-192.

Engle, R., Shephard, N., \& Sheppard, K. (2009). Fitting vast dimensional time-varying covariance models.

Engle, R. F. (1982). Autoregressive conditional heteroscedasticity with estimates of the variance of United Kingdom inflation. Econometrica: Journal of the Econometric Society, 987-1007.

Engle, R. F., \& Sheppard, K. (2001). Theoretical and empirical properties of dynamic conditional correlation multivariate GARCH. Retrieved from SSRN:

Francq, C., \& Zakoïan, J.-M. (2015). Risk-parameter estimation in volatility models. Journal of Econometrics, 184(1), 158-173.

Ftiti, Z., \& Hadhri, S. (2019). Can economic policy uncertainty, oil prices, and investor sentiment predict Islamic stock returns? A multi-scale perspective. Pacific-Basin Finance Journal, 53, 40-55.

Granger, C. W. J. E. J. o. t. E. S. (1969). Investigating causal relations by econometric models and crossspectral methods. Econometrica: Journal of the Econometric Society, 424-438.

Hammoudeh, S., Mensi, W., Reboredo, J. C., \& Nguyen, D. K. (2014). Dynamic dependence of the global Islamic equity index with global conventional equity market indices and risk factors. Pacific-Basin Finance Journal, 30, 189-206.

Jaziri, M., \& Abdelhedi, M. (2018). Islamic occasions and investor sentiment. International Journal of Islamic Middle Eastern Finance Management, 11(2), 194-212.

Joseph, K., Wintoki, M. B., \& Zhang, Z. (2011). Forecasting abnormal stock returns and trading volume using investor sentiment: Evidence from online search. International Journal of Forecasting, 27(4), 1116-1127.

Lanne, M., \& Saikkonen, P. (2007). A multivariate generalized orthogonal factor GARCH model. Journal of Business Economic Statistics, 25(1), 61-75.

Merdad, H. J., Hassan, M. K., \& Hippler, W. J. (2015). The Islamic risk factor in expected stock returns: an empirical study in Saudi Arabia. Pacific-Basin Finance Journal, 34, 293-314.

Miller, E. M. (1977). Risk, uncertainty, and divergence of opinion. The Journal of Finance, 32(4), 11511168.

Narayan, P. K., \& Bannigidadmath, D. (2017). Does financial news predict stock returns? New evidence from Islamic and non-Islamic stocks. Pacific-Basin Finance Journal, 42, 24-45.

Narayan, P. K., \& Phan, D. H. B. (2017). A survey of Islamic banking and finance literature: Issues, challenges and future directions. Pacific-Basin Finance Journal.

Newey, W. K., \& West, K. D. (1986). A simple, positive semi-definite, heteroskedasticity and autocorrelationconsistent covariance matrix. In: National Bureau of Economic Research Cambridge, Mass., USA. 
Perez-Liston, D., Huerta, D., \& Haq, S. (2016). Does investor sentiment impact the returns and volatility of Islamic equities? Journal of Economics Finance, 40(3), 421-437.

Preis, T., Moat, H. S., \& Stanley, H. E. (2013). Quantifying trading behavior in financial markets using Google Trends. Scientific Reports, 3, 1684.

Razak, R. A., Ismail, N., \& Aridi, N. A. (2016). Is Islamic Stock Market No Different than Conventional Stock Market? An Evidence from Malaysia. International Business Management, 10(17), 39143920.

Schröder, M. (2007). Is there a difference? The performance characteristics of SRI equity indices. Journal of Business Finance Accounting, 34(1-2), 331-348.

Shleifer, A., \& Summers, L. H. (1990). The noise trader approach to finance. Journal of Economic Perspectives, 4(2), 19-33.

Shleifer, A., \& Vishny, R. W. (1997). The limits of arbitrage. The Journal of Finance, 52(1), 35-55.

Sibley, S. E., Wang, Y., Xing, Y., \& Zhang, X. (2016). The information content of the sentiment index. Journal of Banking Finance, 62, 164-179.

Singer, E. (2006). Introduction: Nonresponse bias in household surveys. International Journal of Public Opinion Quarterly, 70(5), 637-645.

Solanki, K., \& Seetharam, Y. (2018). Is investor sentiment a relevant factor in determining asset prices? Investment Analysts Journal, 47(3), 243-257.

Sucarrat, G., \& Escribano, A. (2012). Automated Model Selection in Finance: General-to-Specific Modelling of the Mean and Volatility Specifications. Oxford Bulletin of Economics Statistics, 74(5), 716-735.

Sul, H. K., Dennis, A. R., \& Yuan, L. (2017). Trading on twitter: Using social media sentiment to predict stock returns. Decision Sciences, 48(3), 454-488.

Trichilli, Y., Abdelhédi, M., \& Boujelbène, M. A. (2018). Googling Investor's Sentiment: Powerful Measure in Conventional and Islamic MENA Financial Markets. International Economic Journal, 32(3), 454-469.

Vlastakis, N., \& Markellos, R. N. (2012). Information demand and stock market volatility. Journal of Banking Finance, 36(6), 1808-1821.

Vozlyublennaia, N. (2014). Investor attention, index performance, and return predictability. Journal of Banking Finance, 41, 17-35.

Wasiuzzaman, S. (2018). Seasonality in the Saudi stock market: The Hajj effect. The Quarterly Review of Economics Finance, 67, 273-281.

Ye, M., \& Li, G. (2017). Internet big data and capital markets: a literature review. Financial Innovation, 3(1), 6 .

Zhang, X., Fuehres, H., \& Gloor, P. A. (2011). Predicting stock market indicators through twitter "I hope it is not as bad as I fear". Procedia-Social Behavioral Sciences, 26, 55-62.

Zhang, Y., Li, Y., Su, Z., \& Zhang, Z. (2014). Can online searches be used to forecast stock market performance? J Financ Res, 28(1), 1-32. 


\section{Table 1: List of US Islamic stock indices}

\begin{tabular}{|c|c|c|}
\hline Index Code & Index Name & Index Tickers DataStream \\
\hline D1 & DJ ISLAMIC US - PRICE INDEX & DJIMUS\$(PI) \\
\hline D2 & DJ ISLAMIC US MID CAP - PRICE INDEX & DJIUMC\$(PI) \\
\hline D3 & DJ ISLAMIC US LARGE CAP - PRICE INDEX & DJIULC\$(PI) \\
\hline D4 & DJ ISLAMIC US SMALL CAP - PRICE INDEX & DJIUSM\$(PI) \\
\hline D5 & FTSE SHARIA USA \$ - PRICE INDEX & FTSUSA $\$(P I)$ \\
\hline D6 & MSCI AC AMERICAS IS U\$ - PRICE INDEX & MSAMFI\$(PI) \\
\hline D7 & S\&P 500 SHARIA \$ - PRICE INDEX & $\mathrm{SP} 500 \mathrm{~S} \$(\mathrm{PI})$ \\
\hline
\end{tabular}


INVESTMENT ANALYSTS JOURNAL

https://doi.org/10.1080/10293523.2019.1643968

Table 2 Granger Causality: FEARS keywords and returns volatility

\begin{tabular}{|c|c|c|c|c|c|c|c|c|}
\hline FEARS Keywords & Codes & D1D & D2D & D3D & D4D & D5D & D6D & D7D \\
\hline AMERICAN SAVINGS & A3 & 0.0001 & 0.0002 & 0.0002 & 0.0003 & 0.0004 & 0.0006 & 0.0001 \\
\hline BANKRUPTCY & A5 & - & - & - & - & 0.0933 & 0.0724 & - \\
\hline BANKRUPTCY ATTORNEY & A6 & 0.0642 & 0.063 & 0.0622 & 0.0892 & 0.0893 & 0.0798 & 0.068 \\
\hline BANKRUPTCY CHAPTER 7 & A7 & 0.0853 & 0.0942 & 0.0854 & - & - & - & - \\
\hline BANKRUPTCY COURT & A8 & 0.036 & 0.0518 & 0.0385 & 0.0446 & 0.0372 & 0.0266 & 0.0315 \\
\hline BANKRUPTCY LAWS & A10 & 0.0136 & 0.0124 & 0.0145 & 0.0186 & 0.0065 & 0.0165 & 0.0166 \\
\hline BUDGET DEFICIT & A14 & - & 0.0642 & - & - & 0.0804 & 0.0906 & - \\
\hline BUSINESS PARTNERSHIP & A15 & 0.0675 & 0.0578 & 0.0696 & 0.058 & 0.0896 & - & - \\
\hline CAR DONATE & A18 & 0.0051 & 0.0084 & 0.0051 & 0.0093 & 0.0056 & 0.0038 & 0.0129 \\
\hline COOPERATIVE BANK & A26 & - & 0.0374 & - & 0.0466 & - & - & - \\
\hline COST OF LIVING & A28 & 0.0324 & 0.0221 & 0.0289 & 0.0307 & 0.0201 & 0.0204 & 0.0487 \\
\hline DEFAULT & A31 & 0.0838 & 0.0466 & - & 0.0472 & 0.0478 & 0.0757 & 0.0966 \\
\hline DEFERRED COMPENSATION & A32 & 0.0306 & 0.0112 & 0.0391 & 0.0309 & 0.0466 & 0.0293 & 0.0743 \\
\hline DEFICIT & A33 & 0.0097 & 0.013 & 0.0077 & 0.035 & 0.0067 & 0.005 & 0.0129 \\
\hline ENTREPRENEUR & A37 & 0.0977 & 0.0801 & 0.0892 & - & - & - & - \\
\hline ENTREPRENEURIAL & A38 & - & 0.0723 & - & 0.0914 & 0.0696 & 0.0631 & 0.0946 \\
\hline EQUITY & A40 & - & 0.0685 & - & - & - & - & - \\
\hline EQUITY BANK & A41 & 0.0739 & 0.0164 & - & 0.0161 & - & 0.0642 & - \\
\hline EQUITY FUND & A42 & - & 0.0692 & - & 0.0759 & - & - & - \\
\hline EQUITY LINE & A43 & - & 0.0983 & - & & - & - & - \\
\hline GDP & A53 & 0.0561 & 0.0295 & 0.051 & - & 0.0748 & 0.0343 & 0.0614 \\
\hline HEALTH INSURANCE & A58 & - & 0.0805 & - & - & - & - & - \\
\hline HOME EQUITY LINE & A60 & - & 0.0599 & - & - & - & - & - \\
\hline HOUSING ALLOWANCE & A62 & 0.0885 & 0.058 & 0.0973 & 0.0224 & 0.0967 & 0.0593 & 0.0707 \\
\hline INFLATION RATE & A65 & - & - & - & 0.0928 & - & 0.0781 & - \\
\hline LAY OFF & A71 & 0.011 & 0.0206 & 0.0223 & 0.0615 & 0.0133 & 0.0198 & 0.0132 \\
\hline LIMITED PARTNERSHIP & A72 & 0.0383 & 0.0428 & 0.0563 & 0.0342 & 0.0645 & 0.0499 & 0.063 \\
\hline LIQUIDATION & A73 & 0.008 & 0.002 & 0.0135 & 0.0022 & 0.0175 & 0.0099 & 0.0167 \\
\hline
\end{tabular}




\begin{tabular}{|c|c|c|c|c|c|c|c|c|}
\hline MARGIN & A74 & 0.097 & 0.078 & - & 0.0675 & - & 0.0933 & - \\
\hline POOR CREDIT & A77 & 0.0229 & 0.0034 & 0.0704 & 0.002 & 0.0497 & 0.0429 & 0.043 \\
\hline POVERTY LINE & A 80 & - & 0.071 & - & - & 0.0773 & 0.0953 & - \\
\hline POVERTY STATISTICS & A82 & - & 0.0605 & - & - & - & 0.0736 & - \\
\hline PROFITABLE & A87 & 0.013 & 0.004 & 0.0281 & 0.0045 & 0.0228 & 0.0182 & 0.0154 \\
\hline RECESSION & A88 & 0.0797 & - & 0.0677 & - & 0.087 & 0.0587 & 0.0668 \\
\hline SOCIAL SECURITY BENEFIT & A99 & 0.0243 & 0.0108 & 0.0754 & 0.0187 & 0.0784 & 0.0801 & 0.064 \\
\hline SUCCESSFUL BUSINESS & A102 & 0.0769 & 0.0359 & - & 0.0374 & - & - & - \\
\hline UNEMPLOYED & A112 & 0.0437 & - & 0.068 & - & 0.0748 & 0.0612 & 0.0429 \\
\hline WORKERS COMPENSATION INSURANCE & A117 & 0.0116 & 0.0068 & 0.0269 & 0.0048 & 0.046 & 0.0236 & 0.0264 \\
\hline
\end{tabular}


Table 3: Maximum Likelihood Estimates (MLE) for the GARCH model

\begin{tabular}{|c|c|c|c|c|c|c|}
\hline & $\mu$ & $\omega$ & $\gamma$ & $\boldsymbol{\beta}$ & $\log L$ & $\mathbf{D W}$ \\
\hline \multirow[t]{2}{*}{ D1R } & $0.003 * * *$ & $3.03 \mathrm{E}-05^{* * *}$ & $0.283^{* * *}$ & $0.682 * * *$ & 1274.02 & 2.110 \\
\hline & (4.458) & (2.712) & $(7.266)$ & (14.90) & & \\
\hline \multirow[t]{2}{*}{ D2R } & $0.003^{* * *}$ & $3.23 \mathrm{E}-05^{* * *}$ & $0.239 * * *$ & $0.728 * * *$ & 1194.14 & 2.074 \\
\hline & (3.4500) & (3.033) & (7.648) & (18.86) & & \\
\hline \multirow[t]{2}{*}{ D3R } & $0.003 * * *$ & $3.28 \mathrm{E}-05^{* * *}$ & $0.292 * * *$ & $0.666^{* * *}$ & 1288.91 & 2.128 \\
\hline & (4.653) & (2.983) & $(7.761)$ & $(15.01)$ & & \\
\hline \multirow[t]{2}{*}{ D4R } & $0.003 * * *$ & $4.33 \mathrm{E}-05^{* *}$ & $0.268 * * *$ & $0.698^{* * *}$ & 1137.95 & 2.046 \\
\hline & (3.389) & $(2.302)$ & $(6.260)$ & (14.07) & & \\
\hline \multirow[t]{2}{*}{ D5R } & $0.002 * * *$ & $3.36 \mathrm{E}-05^{* * *}$ & $0.327^{* * * *}$ & $0.639^{* * *}$ & 1290.45 & 2.073 \\
\hline & $(4.121)$ & $(2.896)$ & $(7.512)$ & (13.85) & & \\
\hline \multirow[t]{2}{*}{ D6R } & $0.002 * * *$ & $1.92 \mathrm{E}-05^{* *}$ & $0.281^{* * *} *$ & $0.717 * * *$ & 1272.19 & 2.085 \\
\hline & (3.135) & $(2.341)$ & $6.966)$ & (16.87) & & \\
\hline \multirow[t]{2}{*}{ D7R } & $0.003 * * *$ & $2.93 \mathrm{E}-05^{* * *}$ & $0.291 * * *$ & $0.675^{* * *}$ & 1281.47 & 2.092 \\
\hline & $(4.774)$ & $(2.769)$ & $(7.542)$ & $(15.10)$ & & \\
\hline
\end{tabular}


Table 4: FEARS15 and FEEARS30 and Islamic stocks unconditional and conditional volatility (January 2010-December 2017)

\begin{tabular}{|c|c|c|c|c|c|c|c|c|c|c|c|c|c|c|}
\hline VAR & D1D & D2D & D3D & D4D & D5D & D6D & D7D & LAH1 & LAH2 & LAH3 & LAH4 & LAH5 & LAH6 & LAH7 \\
\hline FEARS15 & $-0.00131 * * *$ & $-0.00142^{* * * *}$ & $-0.00127 * * *$ & $-0.00151 * * *$ & $-0.00137^{* * *}$ & $-0.00143 * * *$ & $-0.00128 * * *$ & $-0.362 * * *$ & $-0.384 * * *$ & $-0.362 * * *$ & $-0.339 * * *$ & $-0.327 * *$ & $-0.482 * * *$ & $-0.389 * * *$ \\
\hline R-squared & 0.053 & 0.049 & 0.053 & 0.048 & 0.062 & 0.069 & 0.053 & 0.019 & 0.022 & 0.019 & 0.02 & 0.015 & 0.03 & 0.024 \\
\hline FEARS15L1 & $-0.00125 * * *$ & $-0.00136^{* * * *}$ & $-0.00120^{* * * *}$ & $-0.00148 * * *$ & $-0.00128^{* * *}$ & $-0.00134 * * *$ & $-0.00121^{* * *}$ & $-0.340 * * *$ & $-0.391 * * *$ & $-0.340 * * *$ & $-0.407 * * *$ & $-0.323 * *$ & $-0.455^{* * *}$ & $-0.403 * * *$ \\
\hline R-squared & 0.048 & 0.044 & 0.047 & 0.046 & 0.054 & 0.06 & 0.047 & 0.017 & 0.023 & 0.017 & 0.028 & 0.014 & 0.027 & 0.025 \\
\hline FEARS15L2 & $-0.00134 * * *$ & $-0.00138^{* * *}$ & $-0.00130^{* * *}$ & $-0.00146 * * *$ & $-0.00138^{* * *}$ & $-0.00142 * * *$ & $-0.00131^{* * *}$ & $-0.473 * * *$ & $-0.287^{* *}$ & $-0.473 * * *$ & $-0.326^{* * *}$ & $-0.271 * *$ & $-0.465 * * *$ & $-0.433^{* * *}$ \\
\hline R-squared & 0.055 & 0.046 & 0.055 & 0.044 & 0.062 & 0.067 & 0.055 & 0.033 & 0.012 & 0.033 & 0.018 & 0.01 & 0.028 & 0.029 \\
\hline FEARS15L3 & $-0.00144 * * *$ & $-0.00153^{* * * *}$ & $-0.00139^{* * *}$ & $-0.00165^{* * * *}$ & $-0.00146^{* * *}$ & $-0.00157^{* * * *}$ & $-0.00138^{* * *}$ & $-0.282 * *$ & $-0.304 * *$ & $-0.282 * *$ & $-0.222 *$ & $-0.377^{* * *}$ & $-0.337^{* *}$ & $-0.343 * * *$ \\
\hline R-squared & 0.064 & 0.056 & 0.064 & 0.058 & 0.07 & 0.082 & 0.062 & 0.012 & 0.014 & 0.012 & 0.008 & 0.019 & 0.015 & 0.018 \\
\hline FEARS15L4 & $-0.00157 * * *$ & $-0.00164 * * *$ & $-0.00152^{* * *}$ & $-0.00175^{* * * *}$ & $-0.00160^{* * *}$ & $-0.00171^{* * * *}$ & $-0.00151^{* * *}$ & $-0.350 * * *$ & $-0.329 * * *$ & $-0.350 * * *$ & $-0.295^{* *}$ & $-0.358 * * *$ & $-0.466 * * *$ & $-0.394 * * *$ \\
\hline R-squared & 0.076 & 0.065 & 0.076 & 0.065 & 0.084 & 0.099 & 0.075 & 0.018 & 0.016 & 0.018 & 0.015 & 0.018 & 0.028 & 0.024 \\
\hline FEARS30 & 0.000376 & 0.00033 & 0.000379 & $0.000616^{* *}$ & 0.00038 & $0.000452^{*}$ & 0.00035 & 0.0754 & 0.0737 & 0.0754 & 0.101 & 0.0457 & 0.148 & 0.14 \\
\hline R-squared & 0.006 & 0.003 & 0.006 & 0.011 & 0.006 & 0.009 & 0.005 & 0.001 & 0.001 & 0.001 & 0.002 & 0 & 0.004 & 0.004 \\
\hline FEARS30L1 & 0.000256 & 0.000244 & 0.000249 & $0.000494 *$ & 0.000268 & 0.000349 & 0.000223 & 0.0688 & 0.0937 & 0.0688 & 0.112 & 0.0263 & 0.129 & 0.0815 \\
\hline R-squared & 0.003 & 0.002 & 0.003 & 0.007 & 0.003 & 0.005 & 0.002 & 0.001 & 0.002 & 0.001 & 0.003 & 0 & 0.003 & 0.001 \\
\hline FEARS30L2 & 0.000246 & 0.000201 & 0.000237 & $0.000486^{*}$ & 0.000259 & 0.000335 & 0.000212 & 0.0775 & 0.0946 & 0.0775 & 0.103 & 0.0286 & 0.146 & 0.0957 \\
\hline R-squared & 0.002 & 0.001 & 0.002 & 0.007 & 0.003 & 0.005 & 0.002 & 0.001 & 0.002 & 0.001 & 0.002 & 0 & 0.004 & 0.002 \\
\hline FEARS30L3 & 0.000132 & $6.40 \mathrm{E}-05$ & 0.000126 & 0.00033 & 0.000131 & 0.000222 & 0.000113 & 0.0401 & 0.0997 & 0.0401 & 0.0874 & -0.0239 & 0.118 & 0.0621 \\
\hline R-squared & 0.001 & 0 & 0.001 & 0.003 & 0.001 & 0.002 & 0.001 & 0 & 0.002 & 0 & 0.002 & 0 & 0.002 & 0.001 \\
\hline FEARS30L4 & 0.000182 & $6.19 \mathrm{E}-05$ & 0.000195 & 0.000271 & 0.000182 & 0.000283 & 0.000164 & 0.0626 & 0.00905 & 0.0626 & 0.0469 & -0.052 & 0.103 & 0.0661 \\
\hline R-squared & 0.001 & 0 & 0.002 & 0.002 & 0.001 & 0.004 & 0.001 & 0.001 & 0 & 0.001 & 0 & 0 & 0.002 & 0.001 \\
\hline
\end{tabular}

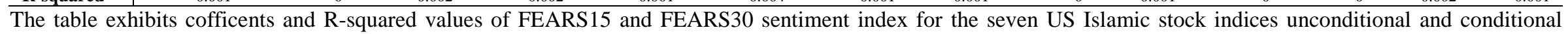

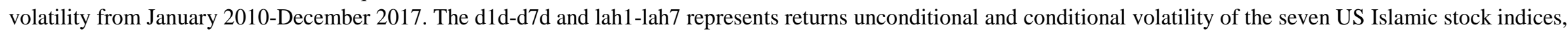

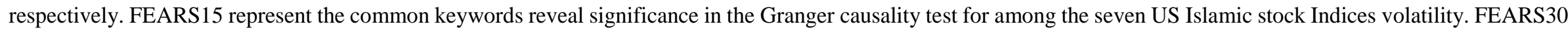
denotes Da et al. (2015) original 30 keywords FEARS index. ***,**,* denote p-values at 1, 5 and 10 percent respectively. 


\section{Table 5: FEARS15 and FEEARS30 sentiment index in- and out-sample}

\begin{tabular}{|c|c|c|c|c|c|c|c|c|c|c|c|c|c|c|}
\hline & D1D & D2D & D3D & D4D & D5D & D6D & D7D & LAH1 & LAH2 & LAH3 & LAH4 & LAH5 & LAH6 & LAH7 \\
\hline \multicolumn{15}{|l|}{$\underline{\text { In-Sample }}$} \\
\hline Root Mean Squared Error & YES & YES & YES & YES & YES & YES & YES & YES & YES & YES & YES & YES & YES & YES \\
\hline Mean Absolute Error & YES & NO & YES & NO & YES & YES & YES & YES & YES & YES & YES & YES & YES & YES \\
\hline Mean Absolute Percentage Error & YES & NO & NO & NO & YES & YES & NO & YES & YES & YES & YES & YES & YES & YES \\
\hline Theil's U & YES & YES & YES & YES & YES & YES & YES & YES & YES & YES & YES & YES & YES & YES \\
\hline Bias Proportion & YES & SAME & YES & SAME & SAME & SAME & YES & SAME & SAME & SAME & SAME & SAME & SAME & SAME \\
\hline Variance Proportion & YES & NO & NO & NO & NO & NO & $\mathrm{NO}$ & YES & YES & YES & YES & YES & YES & YES \\
\hline Covariance Proportion & $\mathrm{NO}$ & YES & YES & YES & YES & YES & YES & YES & YES & YES & YES & YES & YES & YES \\
\hline \multicolumn{15}{|l|}{ Out-of-Sample } \\
\hline Root Mean Squared Error & YES & YES & YES & YES & YES & YES & YES & YES & YES & YES & YES & YES & YES & YES \\
\hline Mean Absolute Error & YES & NO & YES & YES & YES & YES & YES & YES & YES & YES & YES & YES & YES & YES \\
\hline Mean Absolute Percentage Error & YES & YES & YES & NO & YES & YES & YES & YES & YES & YES & YES & YES & YES & YES \\
\hline Theil's U & YES & YES & YES & YES & YES & YES & YES & YES & YES & YES & YES & YES & YES & YES \\
\hline Bias Proportion & YES & YES & YES & YES & YES & YES & YES & YES & NO & YES & YES & NO & YES & YES \\
\hline Variance Proportion & YES & YES & YES & YES & YES & YES & YES & $\mathrm{NO}$ & NO & NO & YES & NO & YES & YES \\
\hline Covariance Proportion & NO & NO & $\mathrm{NO}$ & NO & $\mathrm{NO}$ & NO & $\mathrm{NO}$ & YES & YES & YES & NO & YES & NO & NO \\
\hline
\end{tabular}

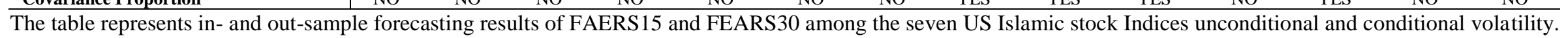

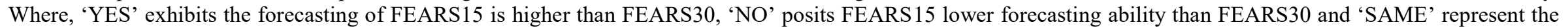

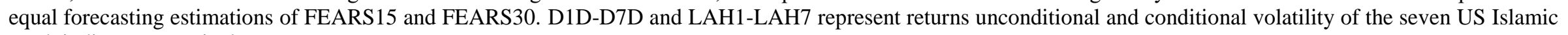
stock indices, respectively. 


\section{Appendix A}

\section{A1: List of 118 FEARS keywords with codes used in the study}

\begin{tabular}{|c|c|c|c|c|c|c|c|c|c|}
\hline Keywords & Codes & Keywords & Codes & Keywords & Codes & Keywords & Codes & Keywords & Codes \\
\hline $401 \mathrm{~K}$ & $\mathrm{~A} 1$ & CONTRIBUTION LIMITS & A25 & FILING BANKRUPTCY & A49 & LIQUIDATION & A73 & SAVINGS CALCULATOR & A97 \\
\hline $401 \mathrm{~K}$ CONTRIBUTION & $\mathrm{A} 2$ & COOPERATIVE BANK & A26 & FINANCIAL CRISIS & A50 & MARGIN & A74 & SOCIAL SECURITY & A98 \\
\hline AMERICAN SAVINGS & $\mathrm{A} 3$ & COST ACCOUNTING & A27 & FOR PROFIT & A51 & NET WORTH & A75 & SOCIAL SECURITY BENEFIT & A99 \\
\hline BANKRUPT & A4 & COST OF LIVING & A28 & FRUGAL & A52 & NON-PROFIT JOBS & A76 & SOCIAL SECURITY CARD & A100 \\
\hline BANKRUPTCY & A5 & CREDITOR & A29 & GDP & A53 & POOR CREDIT & A77 & SOCIAL SECURITY OFFICE & A101 \\
\hline BANKRUPTCY ATTORNEY & A6 & CRISIS & $\mathrm{A} 30$ & GOLD & A54 & POVERTY & A78 & SUCCESSFUL BUSINESS & $\mathrm{A} 102$ \\
\hline BANKRUPTCY CHAPTER 7 & A7 & DEFAULT & $\mathrm{A} 31$ & GOLD PRICE & A55 & POVERTY LEVEL & A79 & TARIFF & A103 \\
\hline BANKRUPTCY COURT & A8 & DEFERRED COMPENSATION & A 32 & GOLD PRICES & A56 & POVERTY LINE & A80 & TARIFFS & A104 \\
\hline BANKRUPTCY LAW & A9 & DEFICIT & A 33 & GREAT DEPRESSION & A57 & POVERTY RATE & A 81 & TAXES & A105 \\
\hline BANKRUPTCY LAWS & $\mathrm{A} 10$ & DEPRESSION & A 34 & HEALTH INSURANCE & A58 & POVERTY STATISTICS & A 82 & THE CRISIS & A106 \\
\hline BARGAIN TRADER & A11 & DONATION & A35 & HOME EQUITY & A59 & PRICE OF GOLD & A83 & THE DEFICIT & A107 \\
\hline BENEFIT & A12 & ECONOMY & A36 & HOME EQUITY LINE & A60 & PRIVATE EQUITY & A 84 & THE DEPRESSION & A108 \\
\hline BENEFITS & A13 & ENTREPRENEUR & A37 & HOME EQUITY LOAN & A61 & PROFIT & A85 & THE GREAT DEPRESSION & A109 \\
\hline BUDGET DEFICIT & A14 & ENTREPRENEURIAL & A38 & HOUSING ALLOWANCE & A62 & PROFIT MARGIN & A86 & THRIFT SAVINGS & A110 \\
\hline BUSINESS PARTNERSHIP & A15 & ENTREPRENEURSHIP & A39 & INFLATION & A63 & PROFITABLE & A87 & TRADE DEFICIT & A111 \\
\hline BUY GOLD & A16 & EQUITY & $\mathrm{A} 40$ & $\begin{array}{l}\text { INFLATION } \\
\text { CALCULATOR }\end{array}$ & A64 & RECESSION & A88 & UNEMPLOYED & A112 \\
\hline CAPITALIZATION & A17 & EQUITY BANK & A41 & INFLATION RATE & A65 & RICH & A89 & UNEMPLOYMENT & A113 \\
\hline CAR DONATE & A18 & EQUITY FUND & A42 & INFLATION RATES & A66 & ROTH CONTRIBUTION & A90 & US DEFICIT & A114 \\
\hline CHAPTER 7 & A19 & EQUITY LINE & A43 & IRA & A67 & ROTH IRA & A91 & US INFLATION & A115 \\
\hline CHAPTER 13 & $\mathrm{~A} 20$ & EQUITY LOAN & A44 & IRA CONTRIBUTION & A68 & $\begin{array}{l}\text { ROTH } \\
\text { CONTRIBUTION }\end{array}$ & A92 & US POVERTY & A116 \\
\hline CHAPTER 13 BANKRUPTCY & $\mathrm{A} 21$ & EXPENSE & A45 & $\begin{array}{ll}\text { IRA } & \text { CONTRIBUTION } \\
\text { LIMITS } & \end{array}$ & A69 & SAVINGS ACCOUNT & A93 & $\begin{array}{l}\text { WORKERS } \\
\text { INSURANCE }\end{array}$ & A117 \\
\hline CHARITY & A22 & EXPENSES & A46 & IRA LIMITS & A70 & SAVINGS & A94 & WORLD POVERTY & A118 \\
\hline COLLEGE SAVINGS & $\mathrm{A} 23$ & FEDERAL POVERTY LEVEL & A47 & LAY OFF & A71 & SAVINGS BOND & A95 & & \\
\hline COMMUNITY BANK & A24 & FILE BANKRUPTCY & A48 & LIMITED PARTNERSHIP & A72 & SAVINGS BONDS & A96 & & \\
\hline
\end{tabular}

The table report the list of 118 keywords used in the Da et al. (2015) study. Also, exhibit codes used for the respective keywords in the paper. 


\section{A2: Regression estimates and t-statistics for one keyword}

\begin{tabular}{|c|c|c|c|c|c|c|c|c|c|c|c|}
\hline \multirow[b]{2}{*}{ Indices } & \multirow[b]{2}{*}{ Keywords } & \multicolumn{3}{|c|}{ Parameter Estimates } & \multirow[b]{2}{*}{ Adj. $R^{2}$} & \multirow[b]{2}{*}{ Indices } & \multirow[b]{2}{*}{ Keywords } & \multicolumn{3}{|c|}{ Parameter Estimates } & \multirow[b]{2}{*}{ Adj. $R^{2}$} \\
\hline & & $\beta_{0}$ & $\beta_{1}$ & $\mathrm{k}_{1}$ & & & & $\beta_{0}$ & $\beta_{1}$ & $\mathrm{k}_{1}$ & \\
\hline \multirow[t]{14}{*}{ D1 } & A3 & $-3.6^{* * *}$ & $2.3 * *$ & $-0.0033 * *$ & 0.0362 & \multirow[t]{14}{*}{ D3 } & $\mathrm{A} 3$ & $-3.61 * * *$ & $2.47 * *$ & $-0.0033 * *$ & 0.0377 \\
\hline & A10 & $-5.75 * * *$ & $2.49 * *$ & $0.0034 * *$ & 0.0391 & & $\mathrm{~A} 10$ & $-5.75 * * *$ & $2.65^{* *}$ & $0.0033^{* *}$ & 0.0405 \\
\hline & A15 & $-3.96 * * *$ & $2.63 * * *$ & $-0.0038 * *$ & 0.0485 & & A15 & $-3.97 * * *$ & $2.79^{* * * *}$ & $-0.0038 * *$ & 0.0499 \\
\hline & A18 & $-3.61 * * *$ & $2.14 * *$ & $-0.0048 * * *$ & 0.0486 & & A18 & $-3.63 * * *$ & $2.29 * *$ & $-0.0048 * * *$ & 0.0496 \\
\hline & $\mathrm{A} 28$ & $-2.01 *$ & $2.18^{* *}$ & $-0.0061 * * *$ & 0.0456 & & $\mathrm{~A} 28$ & $-2.05^{*}$ & $2.33 * * *$ & $-0.006 * * *$ & 0.0468 \\
\hline & A41 & $-3.51 * * *$ & $2.4 * *$ & $-0.0046 * *$ & 0.0438 & & A62 & $-3.91 * * *$ & $2.57 * *$ & $-0.004 * *$ & 0.0442 \\
\hline & A62 & $-3.9^{* * *}$ & $2.41 * *$ & $-0.004 * *$ & 0.0427 & & A72 & $-3.45 * * *$ & $2.79 * * *$ & $-0.0052 * * *$ & 0.0486 \\
\hline & A72 & $-3.44 * * *$ & $2.63 * * *$ & $-0.0052 * * *$ & 0.047 & & A73 & $-3.83 * * *$ & $2.43 * * *$ & $-0.0031 * *$ & 0.0536 \\
\hline & A73 & $-3.82 * * *$ & $2.28 * *$ & $-0.0031 * *$ & 0.0523 & & A87 & $-3.22 * * *$ & $2.45^{* *}$ & $-0.0044 * *$ & 0.0487 \\
\hline & A74 & $-3.98 * * *$ & $2.67 * *$ & $-0.0026^{* *}$ & 0.0404 & & A99 & $-3.37 * * *$ & $2.22 * *$ & $-0.005 * * *$ & 0.0641 \\
\hline & A87 & $-3.2 * * *$ & $2.29 * *$ & $-0.0044 * *$ & 0.0512 & & A117 & $-3.85 * * *$ & $2.58^{* *}$ & $-0.0041 * *$ & 0.0416 \\
\hline & A99 & $-3.35 * * *$ & $2.06^{* * *}$ & $-0.005 * * *$ & 0.059 & & & & & & \\
\hline & A102 & $-3.71 * * *$ & $2.4 * *$ & $-0.0042 * * *$ & 0.0502 & & & & & & \\
\hline & A117 & $-3.84 * * *$ & $2.42 * *$ & $-0.0041 * *$ & 0.0402 & & & & & & \\
\hline \multirow[t]{12}{*}{ D2 } & A3 & $-3.08 * * *$ & $1.96^{*}$ & $-0.0037 * * *$ & 0.0515 & \multirow[t]{12}{*}{ D4 } & $\mathrm{A} 3$ & $-2.34 * * *$ & $1.77 * *$ & $-0.0047 * * *$ & 0.062 \\
\hline & A10 & $-5.72 * * *$ & $2.06^{* *}$ & $0.0048 * * *$ & 0.063 & & $\mathrm{~A} 10$ & $-4.96 * * *$ & $2.09 * * *$ & $0.0029 * *$ & 0.0556 \\
\hline & A18 & $-2.92 * * *$ & $1.81 * *$ & $-0.006 * * *$ & 0.073 & & A18 & $-2.71 * * *$ & $1.77 * * *$ & $-0.0056^{* * *}$ & 0.0768 \\
\hline & A28 & -1.12 & $1.82 * *$ & $-0.0072 * * *$ & 0.0654 & & A28 & $-1.57 *$ & $1.85^{* * *}$ & $-0.0056^{* * *}$ & 0.0626 \\
\hline & A 31 & $-6.72 * * *$ & $2.27 * *$ & $0.0042 * *$ & 0.0542 & & A 31 & $-6.15 * * *$ & $2.2 * * *$ & $0.0037 * *$ & 0.0568 \\
\hline & $\mathrm{A} 32$ & $-3.44 * * *$ & $2.13 * *$ & $-0.0038 * *$ & 0.0528 & & A 32 & $-3.1 * * *$ & $2.05^{* * *}$ & $-0.0038 * *$ & 0.0583 \\
\hline & $\mathrm{A} 40$ & $-2.35^{* *}$ & $2.17 * *$ & $-0.0047 * *$ & 0.054 & & A 38 & $-3.41 * * *$ & $2.02 * * *$ & $-0.0031 * *$ & 0.0574 \\
\hline & A41 & $-3.1 * * *$ & $2.05 * *$ & $-0.0047 * * *$ & 0.0585 & & A41 & $-2.48 * * *$ & $1.92 * * *$ & $-0.0056^{* * *}$ & 0.0719 \\
\hline & A43 & $-2.89 * * *$ & $2.09 * *$ & $-0.0051 * * *$ & 0.0681 & & A42 & $-2.87 * * *$ & $2.08^{* * *}$ & $-0.0046^{* * *}$ & 0.0628 \\
\hline & A60 & $-2.85^{* * *}$ & $2.07 * *$ & $-0.0055^{* * * *}$ & 0.0709 & & A62 & $-3.34 * * *$ & $2.05^{* * * *}$ & $-0.0036^{* *}$ & 0.0594 \\
\hline & A62 & $-3.44 * * *$ & $2.08^{* *}$ & $-0.0044 * * *$ & 0.0596 & & A72 & $-2.99 * * *$ & $2.2 * * *$ & $-0.0044 * *$ & 0.0621 \\
\hline & A73 & $-3.42 * * *$ & $1.95 * *$ & $-0.0032 * *$ & 0.0674 & & A73 & $-3.54 * * *$ & $2.02 * * *$ & $-0.002 * *$ & 0.0583 \\
\hline
\end{tabular}


INVESTMENT ANALYSTS JOURNAL

https://doi.org/10.1080/10293523.2019.1643968

\begin{tabular}{|c|c|c|c|c|c|c|c|c|c|c|c|}
\hline & A77 & $-3.36^{* * *}$ & $1.96^{* *}$ & $-0.0036^{* *}$ & 0.0562 & & A87 & $-2.31 * * *$ & $1.87^{* * * *}$ & $-0.0049^{* * *}$ & 0.0727 \\
\hline & A80 & $-3.84 * * *$ & $2.28 * *$ & $-0.0029 * *$ & 0.0569 & & A99 & $-2.85^{* * *}$ & $1.73 * *$ & $-0.0044 * * *$ & 0.0725 \\
\hline & A87 & $-2.23 * * *$ & $1.85^{* *}$ & $-0.0059 * * *$ & 0.0755 & & A102 & $-3.35 * * *$ & $2.05^{* * * *}$ & $-0.0031 * *$ & 0.0603 \\
\hline & A99 & $-2.93 * * *$ & $1.73^{*}$ & $-0.0052 * * *$ & 0.074 & & A117 & $-3.14 * * *$ & $2.01 * * *$ & $-0.0042^{* *}$ & 0.06 \\
\hline & A102 & $-3.14 * * *$ & $2.00 * *$ & $-0.0049 * * *$ & 0.0714 & & & & & & \\
\hline & A117 & $-3.35 * * *$ & $2.07 * *$ & $-0.0046 * * *$ & 0.0567 & & & & & & \\
\hline \multirow[t]{6}{*}{ D5 } & A3 & $-3.49 * * *$ & $2.33^{* *}$ & $-0.0038^{* *}$ & 0.0377 & \multirow[t]{16}{*}{ D6 } & A3 & $-2.92 * * *$ & $1.96 * *$ & $-0.005^{* * *}$ & 0.0489 \\
\hline & A10 & $-5.95 * * *$ & $2.51 * *$ & $0.0038^{* *}$ & 0.0404 & & A10 & $-6.31 * * *$ & $2.15 * *$ & $0.0058^{* * *}$ & 0.0611 \\
\hline & A18 & $-3.78 * * *$ & $2.23 * *$ & $-0.0046^{* *}$ & 0.045 & & A18 & $-3.08 * * *$ & $1.81 * *$ & $-0.0067 * * *$ & 0.0695 \\
\hline & A28 & $-2.16^{*}$ & $2.25 * *$ & $-0.006^{* * * *}$ & 0.0435 & & A28 & $-1.84 *$ & $1.99 * *$ & $-0.0065^{* *}$ & 0.0516 \\
\hline & A73 & $-4.09 * * *$ & $2.40 * *$ & $-0.0026 * * *$ & 0.0446 & & A 31 & $-7.42 * * *$ & $2.42 * *$ & $0.0049 * *$ & 0.0482 \\
\hline & A80 & $-4.37 * * *$ & $2.69 * *$ & $-0.0026^{* *}$ & 0.0392 & & A32 & $-3.41 * * *$ & $2.2^{* *}$ & $-0.005^{* *}$ & 0.0504 \\
\hline \multirow[t]{10}{*}{ D7 } & A3 & $-3.04 * * *$ & $2.18^{* *}$ & $-0.0046 * * *$ & 0.0489 & & A33 & $-5.69 * * *$ & $2.24 * *$ & $0.0026^{* *}$ & 0.0441 \\
\hline & A10 & $-5.95 * * *$ & $2.45^{* *}$ & $0.0042 * * *$ & 0.0511 & & A41 & $-3.09 * * *$ & $2.12 * *$ & $-0.0058 * * *$ & 0.0568 \\
\hline & A18 & $-3.34 * * *$ & $2.08 * *$ & $-0.0058 * * *$ & 0.0643 & & A73 & $-4.01 * * *$ & $2.17 * *$ & $-0.0026 * * *$ & 0.0499 \\
\hline & A28 & $-1.83^{*}$ & $2.2^{* *}$ & $-0.0065^{* * *}$ & 0.0543 & & A77 & $-3.27 * * *$ & $1.94 * *$ & $-0.0049 * * *$ & 0.0608 \\
\hline & A72 & $-3.74 * * *$ & $2.67 * *$ & $-0.0042 * *$ & 0.0471 & & A80 & $-3.63 * * *$ & $2.38 * *$ & $-0.005 * * *$ & 0.0724 \\
\hline & A73 & $-3.91 * * *$ & $2.35 * *$ & $-0.0028 * *$ & 0.0557 & & A87 & $-2.16 * * *$ & $1.88 * *$ & $-0.007 * * *$ & 0.0768 \\
\hline & A77 & $-3.78 * * *$ & $2.33^{* *}$ & $-0.0034 * *$ & 0.0475 & & A99 & $-3.05 * * *$ & $1.79 * *$ & $-0.0059 * * *$ & 0.0731 \\
\hline & A87 & $-3.08 * * *$ & $2.3^{* * *}$ & $-0.0047 * *$ & 0.0568 & & \multirow[t]{3}{*}{ A117 } & \multirow[t]{3}{*}{$-3.14 * * *$} & \multirow[t]{3}{*}{$2.06^{* *}$} & \multirow[t]{3}{*}{$-0.0067 * * *$} & \multirow[t]{3}{*}{0.0611} \\
\hline & A99 & $-3.35 * * *$ & $2.1 * *$ & $-0.005^{* * *}$ & 0.0665 & & & & & & \\
\hline & A117 & $-3.47 * * *$ & $2.35 * *$ & $-0.0055^{* * *}$ & 0.0587 & & & & & & \\
\hline
\end{tabular}

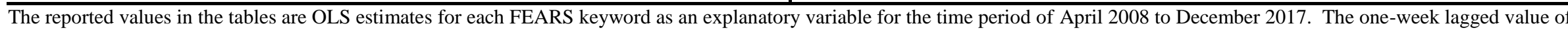

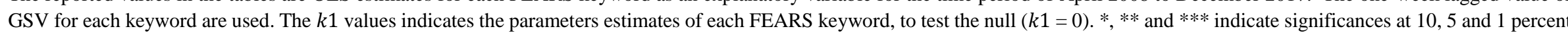
respectively level of significance. 


\section{A3: Regression estimates and t-statistics for two keywords}

\begin{tabular}{|c|c|c|c|c|c|c|c|c|c|c|c|c|c|}
\hline \multirow[b]{2}{*}{ Indices } & \multirow[b]{2}{*}{ Keywords } & \multicolumn{4}{|c|}{ Parameters Estimates } & \multirow[b]{2}{*}{ Adj. $R^{2}$} & \multirow[b]{2}{*}{ Indices } & \multirow[b]{2}{*}{ Keywords } & \multicolumn{4}{|c|}{ Parameters Estimates } & \multirow[b]{2}{*}{ Adj. $R^{2}$} \\
\hline & & $\beta_{0}$ & $\beta_{1}$ & $\mathrm{k} 1$ & $\mathrm{k} 2$ & & & & $\beta_{0}$ & $\beta_{1}$ & $\mathrm{k} 1$ & $\mathrm{k} 2$ & \\
\hline \multirow[t]{11}{*}{ D1 } & $\mathrm{A} 3+\mathrm{A} 74$ & $-2.68 * * *$ & $2.27 * *$ & $-0.003 * *$ & $-0.003 * *$ & 0.045 & \multirow[t]{27}{*}{ D2 } & $\mathrm{A} 3+\mathrm{A} 10$ & $-4.44 * * *$ & $1.77 *$ & $-0.003^{* *}$ & $0.004 * *$ & 0.066 \\
\hline & $\mathrm{A} 10+\mathrm{A} 15$ & $-4.75 * * *$ & $2.4 * * *$ & $0.003^{* *}$ & $-0.004 * *$ & 0.057 & & $\mathrm{~A} 3+\mathrm{A} 40$ & -1.29 & $1.85^{*}$ & $-0.003^{* *}$ & $-0.004 * *$ & 0.058 \\
\hline & $\mathrm{A} 10+\mathrm{A} 28$ & $-2.72 * *$ & $1.92 * *$ & $0.004 * *$ & $-0.006^{* * *}$ & 0.055 & & $\mathrm{~A} 3+\mathrm{A} 80$ & $-2.73 * * *$ & $1.97 * *$ & $-0.003 * *$ & $-0.003 * *$ & 0.06 \\
\hline & $\mathrm{A} 10+\mathrm{A} 62$ & $-4.69 * * *$ & $2.2 * *$ & $0.003 * *$ & $-0.004 * *$ & 0.05 & & $\mathrm{~A} 10+\mathrm{A} 18$ & $-4 * * *$ & $1.65^{*}$ & $0.004^{* *}$ & $-0.005 * * *$ & 0.082 \\
\hline & $\mathrm{A} 10+\mathrm{A} 72$ & $-4.22 * * *$ & $2.4 * *$ & $0.003 * *$ & $-0.005^{* * *}$ & 0.055 & & $\mathrm{~A} 10+\mathrm{A} 28$ & $-2.05 * *$ & $1.45^{*}$ & $0.005^{* * *}$ & $-0.008 * * *$ & 0.086 \\
\hline & $\mathrm{A} 18+\mathrm{A} 28$ & -1.43 & $1.8^{* *}$ & $-0.004 * *$ & $-0.005^{* *}$ & 0.057 & & $\mathrm{~A} 10+\mathrm{A} 32$ & $-4.64 * * *$ & $1.87 * *$ & $0.005^{* *}$ & $-0.003 * *$ & 0.068 \\
\hline & $\mathrm{A} 18+\mathrm{A} 73$ & $-2.81 * * *$ & $1.85^{* *}$ & $-0.004 * *$ & $-0.003 * *$ & 0.064 & & $\mathrm{~A} 10+\mathrm{A} 38$ & $-4.92 * * *$ & $1.81^{*}$ & $0.005^{* * *}$ & $-0.003 * *$ & 0.069 \\
\hline & $\mathrm{A} 18+\mathrm{A} 74$ & $-2.46 * * *$ & $2.06^{* *}$ & $-0.005^{* * *}$ & $-0.003 * *$ & 0.06 & & $\mathrm{~A} 10+\mathrm{A} 40$ & $-3.22 * * *$ & $1.81 *$ & $0.005^{* * *}$ & $-0.005^{* *}$ & 0.075 \\
\hline & $\mathrm{A} 18+\mathrm{A} 102$ & $-2.85^{* * * *}$ & $2^{* *}$ & $-0.004 * *$ & $-0.003 * *$ & 0.06 & & $\mathrm{~A} 10+\mathrm{A} 41$ & $-4.3 * * *$ & $1.82 *$ & $0.004 * *$ & $-0.004 * *$ & 0.072 \\
\hline & $\mathrm{A} 72+\mathrm{A} 73$ & $-2.69 * * *$ & $2.26^{* * *}$ & $-0.004 * *$ & $-0.003 * *$ & 0.062 & & $\mathrm{~A} 10+\mathrm{A} 43$ & $-4.03 * * *$ & $1.86^{*}$ & $0.004^{* *}$ & $-0.005^{* * *}$ & 0.08 \\
\hline & $\mathrm{A} 73+\mathrm{A} 102$ & $-3.13 * * *$ & $2.14 * *$ & $-0.002 * *$ & $-0.003 * *$ & 0.061 & & $\mathrm{~A} 10+\mathrm{A} 60$ & $-3.97 * * *$ & $1.83^{*}$ & $0.004^{* *}$ & $-0.005^{* * *}$ & 0.084 \\
\hline \multirow[t]{13}{*}{ D3 } & $\mathrm{A} 10+\mathrm{A} 15$ & $-4.76 * * *$ & $2.55^{* * *}$ & $0.003 * *$ & $-0.004 * *$ & 0.058 & & A10+A62 & $-4.55^{* * *}$ & $1.79 *$ & $0.005^{* * *}$ & $-0.004 * * *$ & 0.077 \\
\hline & $\mathrm{A} 10+\mathrm{A} 28$ & $-2.76^{* *}$ & $2.06^{* *}$ & $0.004 * *$ & $-0.006^{* * *}$ & 0.056 & & $\mathrm{~A} 10+\mathrm{A} 73$ & $-4.49 * * *$ & $1.77 *$ & $0.004^{* *}$ & $-0.003^{* *}$ & 0.077 \\
\hline & $\mathrm{A} 10+\mathrm{A} 62$ & $-4.69 * * *$ & $2.35^{* *}$ & $0.003^{* *}$ & $-0.004 * *$ & 0.051 & & A10+A87 & $-3.37 * * *$ & $1.68 *$ & $0.004 * *$ & $-0.005^{* * *}$ & 0.085 \\
\hline & $\mathrm{A} 10+\mathrm{A} 72$ & $-4.23 * * *$ & $2.56^{* * * *}$ & $0.003^{* *}$ & $-0.005^{* * *}$ & 0.056 & & $\mathrm{~A} 10+\mathrm{A} 102$ & $-4.23 * * *$ & $1.76^{*}$ & $0.004^{* *}$ & $-0.005^{* * *}$ & 0.084 \\
\hline & $\mathrm{A} 10+\mathrm{A} 74$ & $-4.77 * * *$ & $2.6^{* *}$ & $0.003^{* *}$ & $-0.003 * *$ & 0.049 & & $\mathrm{~A} 10+\mathrm{A} 117$ & $-4.56 * * *$ & $1.85^{*}$ & $0.004 * *$ & $-0.004 * *$ & 0.07 \\
\hline & $\mathrm{A} 18+\mathrm{A} 28$ & -1.47 & $1.94 * *$ & $-0.004 * *$ & $-0.005 * *$ & 0.058 & & $\mathrm{~A} 18+\mathrm{A} 28$ & -0.32 & $1.44 *$ & $-0.005 * * *$ & $-0.006^{* * *}$ & 0.085 \\
\hline & $\mathrm{A} 18+\mathrm{A} 72$ & $-2.22 * * *$ & $2.23 * * *$ & $-0.005^{* * * *}$ & $-0.005^{* * *}$ & 0.064 & & $\mathrm{~A} 18+\mathrm{A} 40$ & -0.59 & $1.6^{*}$ & $-0.006 * * *$ & $-0.005 * *$ & 0.082 \\
\hline & $\mathrm{A} 18+\mathrm{A} 73$ & $-2.84 * * *$ & $1.99^{* *}$ & $-0.004^{* * *}$ & $-0.003 * *$ & 0.065 & & $\mathrm{~A} 18+\mathrm{A} 43$ & $-1.82^{* *}$ & $1.67 *$ & $-0.005^{* * *}$ & $-0.004 * * *$ & 0.086 \\
\hline & $\mathrm{A} 18+\mathrm{A} 74$ & $-2.48 * * *$ & $2.2 * * *$ & $-0.005 * * *$ & $-0.003 * *$ & 0.061 & & A18+A60 & $-1.98 * * *$ & $1.71^{*}$ & $-0.005 * * *$ & $-0.004 * * *$ & 0.085 \\
\hline & $\mathrm{A} 18+\mathrm{A} 102$ & $-2.87 * * *$ & $2.15^{* *}$ & $-0.004^{* *} *$ & $-0.003 * *$ & 0.061 & & $\mathrm{~A} 18+\mathrm{A} 62$ & $-2.24 * * *$ & $1.66^{*}$ & $-0.005^{* * *}$ & $-0.003^{* *}$ & 0.08 \\
\hline & $\mathrm{A} 28+\mathrm{A} 72$ & -1.59 & $2.4 * * *$ & $-0.005^{*}$ & $-0.004 * *$ & 0.055 & & $\mathrm{~A} 18+\mathrm{A} 73$ & $-2.07 * * *$ & $1.5^{*}$ & $-0.005 * * *$ & $-0.003 * *$ & 0.088 \\
\hline & $\mathrm{A} 72+\mathrm{A} 73$ & $-2.7 * * *$ & $2.42 * * *$ & $-0.004 * *$ & $-0.003^{* *}$ & 0.064 & & A18+A87 & $-1.58^{*}$ & $1.57 *$ & $-0.004 * * *$ & $-0.004 * *$ & 0.087 \\
\hline & $\mathrm{A} 73+\mathrm{A} 102$ & $-3.15^{* * * *}$ & $2.29 * *$ & $-0.002 * *$ & $-0.003^{* *}$ & 0.062 & & A18+A99 & $-2.14 * * *$ & $1.49 *$ & $-0.004 * * *$ & $-0.004 * * *$ & 0.086 \\
\hline \multirow[t]{3}{*}{ D4 } & $\mathrm{A} 3+\mathrm{A} 18$ & $-1.65^{* *}$ & $1.51 * *$ & $-0.003 * *$ & $-0.005^{* * *}$ & 0.081 & & $\mathrm{~A} 18+\mathrm{A} 102$ & $-2 * * *$ & $1.6^{*}$ & $-0.005^{* * *}$ & $-0.004 * *$ & 0.089 \\
\hline & $\mathrm{A} 3+\mathrm{A} 28$ & -0.38 & $1.49^{* *}$ & $-0.004 * * *$ & $-0.005^{* *}$ & 0.07 & & $\mathrm{~A} 28+\mathrm{A} 31$ & $-3.26 * *$ & $1.7^{* *}$ & $-0.007 * * *$ & $0.004 * *$ & 0.075 \\
\hline & $\mathrm{A} 3+\mathrm{A} 41$ & $-1.51 * *$ & $1.64 * *$ & $-0.003 * *$ & $-0.005^{* * *}$ & 0.076 & & $\mathrm{~A} 28+\mathrm{A} 43$ & -0.94 & $1.78 * *$ & $-0.005^{* *}$ & $-0.004 * *$ & 0.075 \\
\hline
\end{tabular}




\begin{tabular}{|c|c|c|c|c|c|c|c|c|c|c|c|c|c|}
\hline & $\mathrm{A} 3+\mathrm{A} 42$ & $-1.68 * *$ & $1.73 * *$ & $-0.004 * *$ & $-0.004 * *$ & 0.069 & & A28+A62 & -0.8 & $1.69 *$ & $-0.006 * *$ & $-0.003 * *$ & 0.072 \\
\hline & $\mathrm{A} 3+\mathrm{A} 72$ & $-1.7 * *$ & $1.8^{* *}$ & $-0.004 * *$ & $-0.004 * *$ & 0.069 & & A28+A73 & -0.99 & $1.61 * *$ & $-0.006 * *$ & $-0.003 * *$ & 0.077 \\
\hline & $\mathrm{A} 10+\mathrm{A} 28$ & $-2.14 * *$ & $1.62 * * *$ & $0.003 * *$ & $-0.006^{* * *}$ & 0.071 & & $\mathrm{~A} 28+\mathrm{A} 102$ & -0.93 & $1.68^{*}$ & $-0.005^{* *}$ & $-0.004 * *$ & 0.08 \\
\hline & $\mathrm{A} 10+\mathrm{A} 38$ & $-4.08 * * *$ & $1.82 * * *$ & $0.003 * *$ & $-0.003 * *$ & 0.064 & & $\mathrm{~A} 31+\mathrm{A} 40$ & $-4.43^{* * *}$ & $2.03 * *$ & $0.005^{* *}$ & $-0.005 * * *$ & 0.066 \\
\hline & $\mathrm{A} 10+\mathrm{A} 62$ & $-4 * * *$ & $1.87 * * *$ & $0.003 * *$ & $-0.004 * *$ & 0.065 & & $\mathrm{~A} 31+\mathrm{A} 60$ & $-4.99 * * *$ & $1.97 * *$ & $0.004 * *$ & $-0.006 * * *$ & 0.08 \\
\hline & $\mathrm{A} 10+\mathrm{A} 72$ & $-3.66 * * *$ & $2.01 * * *$ & $0.003 * *$ & $-0.004 * *$ & 0.069 & & $\mathrm{~A} 31+\mathrm{A} 62$ & $-5.62 * * *$ & $1.97 * *$ & $0.004 * *$ & $-0.005^{* * *}$ & 0.069 \\
\hline & $\mathrm{A} 18+\mathrm{A} 28$ & -0.8 & $1.5 * * *$ & $-0.005 * * *$ & $-0.004 * *$ & 0.083 & & $\mathrm{~A} 31+\mathrm{A} 80$ & $-5.9 * * *$ & $2.19 * *$ & $0.004 * *$ & $-0.003 * *$ & 0.065 \\
\hline & $\mathrm{A} 18+\mathrm{A} 87$ & $-1.68 * *$ & $1.6^{* * *}$ & $-0.004 * * *$ & $-0.003 * *$ & 0.086 & & $\mathrm{~A} 43+\mathrm{A} 80$ & $-2.75 * * *$ & $2.09 * *$ & $-0.004 * *$ & $-0.002 * *$ & 0.066 \\
\hline & A18+A99 & $-2.08 * * *$ & $1.51^{* *}$ & $-0.004 * * *$ & $-0.003 * *$ & 0.085 & & $\mathrm{~A} 43+\mathrm{A} 82$ & $-2.4 * * *$ & $2.1 * *$ & $-0.005 * * *$ & $-0.003 * *$ & 0.071 \\
\hline & A28+A31 & $-3.43^{* * *}$ & $1.76^{* * *}$ & $-0.006 * * *$ & $0.004 * *$ & 0.071 & & A60+A62 & $-2.19^{* * *}$ & $1.89 * *$ & $-0.005^{* * *}$ & $-0.003 * *$ & 0.078 \\
\hline & $\mathrm{A} 28+\mathrm{A} 102$ & -1.46 & $1.78 * * *$ & $-0.004 * *$ & $-0.002 *$ & 0.067 & & $\mathrm{~A} 60+\mathrm{A} 73$ & $-2.27 * * *$ & $1.8^{* *}$ & $-0.004 * * *$ & $-0.002 * *$ & 0.082 \\
\hline & $\mathrm{A} 31+\mathrm{A} 38$ & $-5.2 * * *$ & $1.97 * * *$ & $0.003 * *$ & $-0.003 * *$ & 0.064 & & $\mathrm{~A} 60+\mathrm{A} 102$ & $-2.29 * * *$ & $1.89 * *$ & $-0.004 * * *$ & $-0.004 * *$ & 0.081 \\
\hline & $\mathrm{A} 31+\mathrm{A} 62$ & $-5.25 * * *$ & $1.96 * * *$ & $0.004 * *$ & $-0.004 * *$ & 0.068 & & $\mathrm{~A} 62+\mathrm{A} 73$ & $-2.67 * * *$ & $1.78^{*}$ & $-0.003 * *$ & $-0.003^{* *}$ & 0.075 \\
\hline & $\mathrm{A} 31+\mathrm{A} 72$ & $-4.92 * * *$ & $2.11 * * *$ & $0.004 * *$ & $-0.005 * * *$ & 0.071 & & $\mathrm{~A} 62+\mathrm{A} 102$ & $-2.47 * * *$ & $1.84 *$ & $-0.003 * *$ & $-0.004 * * *$ & 0.078 \\
\hline & A41+A87 & $-1.68 * *$ & $1.75 * * *$ & $-0.004 * *$ & $-0.003 * *$ & 0.08 & & $\mathrm{~A} 62+\mathrm{A} 117$ & $-2.66^{* * * *}$ & $1.9^{*}$ & $-0.004 * *$ & $-0.004 * *$ & 0.065 \\
\hline & A41+A99 & $-2.11 * * *$ & $1.67 * * *$ & $-0.004 * *$ & $-0.003 * *$ & 0.079 & & $\mathrm{~A} 73+\mathrm{A} 102$ & $-2.54 * * *$ & $1.76^{* *}$ & $-0.002 * *$ & $-0.004 * *$ & 0.082 \\
\hline D5 & A10+A28 & $-2.96 * *$ & $1.98^{* *}$ & $0.004 * * *$ & $-0.006 * *$ & 0.054 & D6 & $\mathrm{A} 3+\mathrm{A} 10$ & $-4.55 * * *$ & $1.75^{*}$ & $-0.004 * *$ & $0.005 * * *$ & 0.068 \\
\hline & $\mathrm{A} 18+\mathrm{A} 28$ & -1.62 & $1.91 * * *$ & $-0.004 * *$ & $-0.005 * *$ & 0.052 & & $\mathrm{~A} 3+\mathrm{A} 28$ & -0.69 & $1.63 * *$ & $-0.004 * *$ & $-0.005^{* *}$ & 0.058 \\
\hline & $\mathrm{A} 18+\mathrm{A} 73$ & $-3.11 * * *$ & $2 * * *$ & $-0.004 * *$ & $-0.002 * *$ & 0.054 & & $\mathrm{~A} 3+\mathrm{A} 102$ & $-2.51 * * *$ & $1.87 * *$ & $-0.004 * *$ & $-0.003^{* *}$ & 0.058 \\
\hline & $\mathrm{A} 33+\mathrm{A} 74$ & $-4.68 * * *$ & $2.26 * * *$ & $0.004 * *$ & $-0.004 * *$ & 0.045 & & $\mathrm{~A} 10+\mathrm{A} 18$ & $-4.41 * * *$ & $1.65 * *$ & $0.004 * * *$ & $-0.006 * * *$ & 0.083 \\
\hline & $\mathrm{A} 33+\mathrm{A} 102$ & $-4.58 * * *$ & $2.15^{* * *}$ & $0.003^{* *}$ & $-0.004 * * *$ & 0.048 & & $\mathrm{~A} 10+\mathrm{A} 28$ & $-3 * * *$ & $1.58 * *$ & $0.006 * * *$ & $-0.007 * * *$ & 0.078 \\
\hline D7 & $\mathrm{A} 3+\mathrm{A} 28$ & -0.83 & $1.85 * *$ & $-0.004 * *$ & $-0.005 * *$ & 0.06 & & $\mathrm{~A} 10+\mathrm{A} 32$ & $-4.86^{* * *}$ & $1.92 * *$ & $0.005 * * *$ & $-0.004 * *$ & 0.071 \\
\hline & A3+A117 & $-2.44 * * *$ & $2.04 * *$ & $-0.003 * *$ & $-0.004 * *$ & 0.059 & & A10+A41 & $-4.54 * * *$ & $1.85^{* *}$ & $0.005 * * *$ & $-0.005^{* * *}$ & 0.075 \\
\hline & $\mathrm{A} 10+\mathrm{A} 15$ & $-5.17 * * *$ & $2.39 * *$ & $0.004 * * *$ & $-0.003 * *$ & 0.062 & & $\mathrm{~A} 10+\mathrm{A} 72$ & $-4.94 * * *$ & $2.06 * *$ & $0.006 * * *$ & $-0.005^{* *}$ & 0.073 \\
\hline & $\mathrm{A} 10+\mathrm{A} 18$ & $-4.26 * * *$ & $1.96^{* *}$ & $0.003^{* *}$ & $-0.005^{* * *}$ & 0.07 & & $\mathrm{~A} 10+\mathrm{A} 80$ & $-4.86^{* * *}$ & $2.12 * *$ & $0.004 * * *$ & $-0.004 * * *$ & 0.085 \\
\hline & $\mathrm{A} 10+\mathrm{A} 28$ & $-2.72 * *$ & $1.88^{* *}$ & $0.004 * * *$ & $-0.007 * * *$ & 0.071 & & A10+A87 & $-3.55 * * *$ & $1.7 * *$ & $0.004 * * *$ & $-0.006^{* * *}$ & 0.089 \\
\hline & $\mathrm{A} 10+\mathrm{A} 72$ & $-4.72 * * *$ & $2.39^{* *}$ & $0.004 * * *$ & $-0.004 * *$ & 0.062 & & A10+A102 & $-5.14 * * *$ & $1.93 * *$ & $0.005^{* * *}$ & $-0.004 * *$ & 0.072 \\
\hline & $\mathrm{A} 10+\mathrm{A} 73$ & $-4.85 * * *$ & $2.19 * *$ & $0.003 * *$ & $-0.002 * *$ & 0.063 & & A10+A117 & $-4.55 * * *$ & $1.83 * *$ & $0.005^{* * *} *$ & $-0.006 * * *$ & 0.078 \\
\hline & A10+A87 & $-4.13 * * *$ & $2.15^{* *}$ & $0.003 * *$ & $-0.004 * *$ & 0.064 & & $\mathrm{~A} 18+\mathrm{A} 28$ & -0.94 & $1.5^{* *}$ & $-0.006^{* * *}$ & $-0.005^{* *}$ & 0.076 \\
\hline & $\mathrm{A} 10+\mathrm{A} 102$ & $-4.81 * * *$ & $2.24^{* *}$ & $0.004 * *$ & $-0.003 * *$ & 0.064 & & A18+A41 & $-2.24 * * *$ & $1.69 * *$ & $-0.006^{* * *}$ & $-0.004 * *$ & 0.075 \\
\hline & A10+A117 & $-4.48^{* * * *}$ & $2.17^{* *}$ & $0.004 * *$ & $-0.005^{* *}$ & 0.064 & & A18+A73 & $-2.47 * * *$ & $1.6 * *$ & $-0.006^{* * *}$ & $-0.002 * *$ & 0.077 \\
\hline
\end{tabular}


INVESTMENT ANALYSTS JOURNAL

https://doi.org/10.1080/10293523.2019.1643968

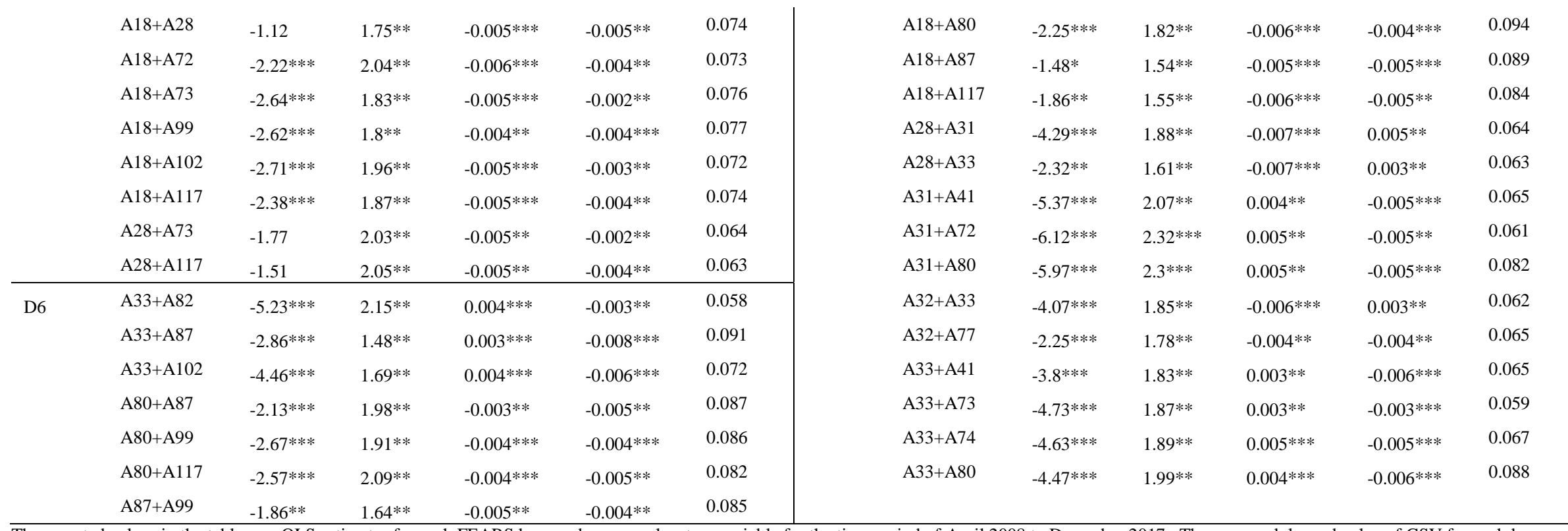

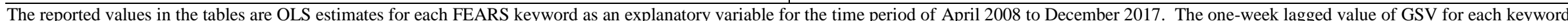

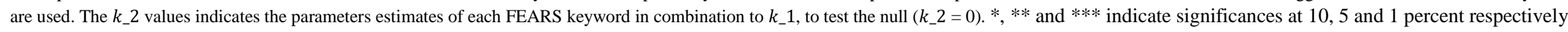
level of significance. 


\section{A4: OLS estimates of three keywords as explanatory variables}

\begin{tabular}{|c|c|c|c|c|c|c|c|c|c|c|c|c|c|c|c|}
\hline \multirow[b]{2}{*}{ indices } & \multirow[b]{2}{*}{ Keywords } & \multicolumn{5}{|c|}{ Parameters Estimates } & \multirow[b]{2}{*}{ Adj. $R^{2}$} & \multirow[b]{2}{*}{ indices } & \multirow[b]{2}{*}{ Keywords } & \multicolumn{5}{|c|}{ Parameters Estimates } & \multirow[b]{2}{*}{ Adj. $R^{2}$} \\
\hline & & $\beta_{0}$ & $\beta_{1}$ & k1 & $\mathrm{k} 2$ & $\mathrm{k} 3$ & & & & $\beta_{0}$ & $\beta_{1}$ & k1 & $\mathrm{k} 2$ & k3 & \\
\hline \multirow[t]{3}{*}{ D1 } & $\mathrm{A} 10+\mathrm{A} 28+\mathrm{A} 72$ & $-2.27 *$ & $1.99 * *$ & $0.004 * *$ & $-0.005^{* *}$ & $-0.004 * *$ & 0.062 & \multirow[t]{22}{*}{ D6 } & $\mathrm{A} 10+\mathrm{A} 18+\mathrm{A} 28$ & $-2.07 *$ & $1.27 *$ & $0.005^{* * *}$ & $0.005^{* * *}$ & $-0.006^{* *}$ & 0.092 \\
\hline & $\mathrm{A} 18+\mathrm{A} 73+\mathrm{A} 72$ & $-1.71 * *$ & $1.84 * *$ & $-0.004 * *$ & $-0.002 * *$ & $-0.004 * *$ & 0.073 & & $\mathrm{~A} 10+\mathrm{A} 18+\mathrm{A} 40$ & -1.47 & $1.34 *$ & $0.005 * * *$ & $\overline{0.006 * * *}$ & $\overline{0.006 * * *}$ & 0.098 \\
\hline & $\mathrm{A} 18+\mathrm{A} 73+\mathrm{A} 74$ & $-1.74 *$ & $1.79^{* *}$ & $-0.004 * * *$ & $-0.003 * *$ & $-0.003 * *$ & 0.074 & & $\mathrm{~A} 10+\mathrm{A} 18+\mathrm{A} 42$ & $-2.5 * * *$ & $1.49 * *$ & $0.004 * *$ & $-\overline{0.005 * * *}$ & $\overline{0}-006 * * *$ & 0.1 \\
\hline \multirow[t]{19}{*}{ D2 } & $\mathrm{A} 10+\mathrm{A} 18+\mathrm{A} 62$ & $-3.33 * * *$ & $1.49 *$ & $0.004 * *$ & $-0.004 * * *$ & $-0.003 * *$ & 0.089 & & $\mathrm{~A} 10+\mathrm{A} 18+\mathrm{A} 43$ & $-\overline{3.06 * * *}$ & $1.51 * *$ & $0.004 * * *$ & $\overline{0.005 * * *}$ & $\overline{0} .004 * * *$ & 0.097 \\
\hline & $\mathrm{A} 10+\mathrm{A} 18+\mathrm{A} 102$ & $-3.04 * * *$ & $1.47 *$ & $0.003 * *$ & $-0.004 * * *$ & $-0.004 * *$ & 0.096 & & $\mathrm{~A} 10+\mathrm{A} 18+\mathrm{A} 60$ & $\overline{3} .53 * * *$ & $1.57 * *$ & $0.004 * * *$ & $\overline{-} 0.005 * * *$ & $-0.004 * *$ & 0.091 \\
\hline & $\mathrm{A} 10+\mathrm{A} 40+\mathrm{A} 18$ & -1.53 & $1.4^{*}$ & $0.004 * *$ & $-0.005^{* *}$ & $-0.005 * * *$ & 0.093 & & $\mathrm{~A} 10+\mathrm{A} 18+\mathrm{A} 80$ & $-\overline{3.38 * * *}$ & $1.69^{* *}$ & $0.003 * *$ & $\overline{-}-005^{* * * *}$ & $\overline{-}-004 * * *$ & 0.101 \\
\hline & $\mathrm{A} 10+\mathrm{A} 40+\mathrm{A} 62$ & $-2.73^{* *}$ & $1.63^{*}$ & $0.005 * * *$ & $-0.004 * *$ & $-0.004 * *$ & 0.083 & & $\mathrm{~A} 10+\mathrm{A} 18+\mathrm{A} 87$ & $-\overline{2.77 * * *}$ & $1.43 * *$ & $0.004 * * *$ & $\overline{-}-004 * * *$ & $\overline{-}-005^{* * *}$ & 0.098 \\
\hline & $\mathrm{A} 10+\mathrm{A} 43+\mathrm{A} 62$ & $-3.48 * * *$ & $1.7^{*}$ & $0.004 * *$ & $-0.004 * *$ & $-0.003^{* *}$ & 0.086 & & $\mathrm{~A} 10+\mathrm{A} 18+\mathrm{A} 99$ & $-\overline{3.42 * * *}$ & $1.39 *$ & $0.004 * *$ & $\overline{-}-004 * * *$ & $-\overline{0.004 * * *}$ & 0.094 \\
\hline & $\mathrm{A} 10+\mathrm{A} 43+\mathrm{A} 102$ & $-3.15 * * *$ & $1.66^{*}$ & $0.004 * *$ & $-0.004 * *$ & $-0.004 * *$ & 0.093 & & $\mathrm{~A} 10+\mathrm{A} 18+\mathrm{A} 117$ & 3.17*** & $1.44 *$ & $0.004 * * *$ & $\overline{0}-005 * * *$ & $-0.005 * *$ & 0.093 \\
\hline & $\mathrm{A} 10+\mathrm{A} 60+\mathrm{A} 18$ & $-3.04 * * *$ & $1.56^{*}$ & $0.003 * *$ & $-0.004 * * *$ & $-0.004 * *$ & 0.093 & & $\mathrm{~A} 10+\mathrm{A} 28+\mathrm{A} 33$ & $-\overline{3.34 * * *}$ & $1.28 *$ & $0.006 * * *$ & $\overline{-}-008 * * *$ & $0.003 * *$ & 0.086 \\
\hline & $\mathrm{A} 10+\mathrm{A} 60+\mathrm{A} 28$ & $-2.12 * *$ & $1.49^{*}$ & $0.005 * * *$ & $-0.003 * *$ & $-0.005 * *$ & 0.091 & & $\mathrm{~A} 10+\mathrm{A} 32+\mathrm{A} 33$ & $\overline{5.31 * * *}$ & $1.64 * *$ & $0.005 * * *$ & $-0.005^{* *}$ & $0.003 * *$ & 0.078 \\
\hline & $\mathrm{A} 10+\mathrm{A} 60+\mathrm{A} 62$ & $-3.31 * * *$ & $1.64^{*}$ & $0.004 * *$ & $-0.004 * * *$ & $-0.003 * *$ & 0.091 & & $\mathrm{~A} 10+\mathrm{A} 72+\mathrm{A} 33$ & $\overline{5.35^{* * *}}$ & $1.75 * *$ & $0.005 * * *$ & $-0.006^{* *}$ & $0.003 * *$ & 0.084 \\
\hline & $\mathrm{A} 10+\mathrm{A} 60+\mathrm{A} 87$ & $-2.59 * * *$ & $1.59 *$ & $0.004 * *$ & $-0.004 * * *$ & $-0.004 * *$ & 0.095 & & $\mathrm{~A} 10+\mathrm{A} 80+\mathrm{A} 33$ & $5.42 * * *$ & $1.82 * *$ & $0.004 * *$ & $0.005 * * *$ & $0.003 * * *$ & 0.097 \\
\hline & $\mathrm{A} 10+\mathrm{A} 62+\mathrm{A} 18$ & $-3.33 * * *$ & $1.49^{*}$ & $0.004 * *$ & $-0.003 * *$ & $-0.004 * * *$ & 0.089 & & $\mathrm{~A} 10+\mathrm{A} 80+\mathrm{A} 42$ & $\overline{3.76 * * *}$ & $2 * *$ & $0.004 * * *$ & $-0.003 * *$ & $-0.004 * *$ & 0.092 \\
\hline & $\mathrm{A} 10+\mathrm{A} 62+\mathrm{A} 28$ & -1.73 & 1.33 & $0.005 * * *$ & $-0.003 * *$ & $-0.007 * * *$ & 0.092 & & $\mathrm{~A} 10+\mathrm{A} 80+\mathrm{A} 43$ & - $3.34 * * *$ & $1.91 * *$ & $0.004 * *$ & $0.004 * * *$ & $\overline{0} .005^{* * *}$ & 0.1 \\
\hline & $\mathrm{A} 10+\mathrm{A} 62+\mathrm{A} 40$ & $-2.73^{* *}$ & $1.63^{*}$ & $0.005 * * *$ & $-0.004 * *$ & $-0.004 * *$ & 0.083 & & $\mathrm{~A} 10+\mathrm{A} 80+\mathrm{A} 60$ & $-\overline{3.59 * * *}$ & $1.92 * *$ & $0.004 * * *$ & $\overline{-}-004 * * *$ & $\overline{-}-004 * * *$ & 0.097 \\
\hline & $\mathrm{A} 10+\mathrm{A} 62+\mathrm{A} 43$ & $-3.48 * * *$ & $1.7^{*}$ & $0.004 * *$ & $-0.003 * *$ & $-0.004 * *$ & 0.086 & & A10+A80+A99 & $3.84 * * *$ & $1.77 * *$ & $0.004 * *$ & $-0.003 * *$ & $-0.004 * *$ & 0.095 \\
\hline & $\mathrm{A} 10+\mathrm{A} 62+\mathrm{A} 73$ & $-3.74 * * *$ & $1.6^{*}$ & $0.004 * *$ & $-0.004 * *$ & $-0.002 *$ & 0.085 & & $\mathrm{~A} 10+\mathrm{A} 87+\mathrm{A} 33$ & $\overline{-} 3.98 * * *$ & $1.36^{*}$ & $0.004 * * *$ & $\overline{-}-007 * * *$ & $0.003 * * *$ & 0.1 \\
\hline & $\mathrm{A} 10+\mathrm{A} 62+\mathrm{A} 102$ & $-3.56^{* * *}$ & $1.6^{*}$ & $0.004 * *$ & $-0.003 * *$ & $-0.004 * *$ & 0.091 & & $\mathrm{~A} 10+\mathrm{A} 87+\mathrm{A} 43$ & 2.86*** & $1.63^{* *}$ & $0.004 * * *$ & $\overline{0.005 * * *}$ & $-0.004 * *$ & 0.096 \\
\hline & $\mathrm{A} 10+\mathrm{A} 102+\mathrm{A} 18$ & $-3.04 * * *$ & $1.47 *$ & $0.003 * *$ & $-0.004 * *$ & $-0.004 * * *$ & 0.096 & & $\mathrm{~A} 10+\mathrm{A} 87+\mathrm{A} 60$ & $-\overline{2.86 * * *}$ & $1.61 * *$ & $0.004 * * *$ & $\overline{-}-005 * * *$ & $-0.003 * *$ & 0.096 \\
\hline & $\mathrm{A} 10+\mathrm{A} 102+\mathrm{A} 43$ & $-3.15^{* * *}$ & $1.66^{*}$ & $0.004 * *$ & $-0.004 * *$ & $-0.004 * *$ & 0.093 & & A10+A87+A99 & $3.13 * * *$ & $1.52 * *$ & $0.004 * * *$ & $-0.004 * *$ & $-0.003 * *$ & 0.094 \\
\hline & $\mathrm{A} 10+\mathrm{A} 102+\mathrm{A} 62$ & $-3.56 * * *$ & $1.6^{*}$ & $0.004 * *$ & $-0.004 * *$ & $-0.003 * *$ & 0.091 & & $\mathrm{~A} 10+\mathrm{A} 102+\mathrm{A} 33$ & $5.57 * * *$ & $1.51 *$ & $0.005 * * *$ & $0.005^{* * *}$ & $0.004 * * *$ & 0.086 \\
\hline
\end{tabular}




\begin{tabular}{|c|c|c|c|c|c|c|c|c|c|c|c|c|c|}
\hline $\mathrm{A} 18+\mathrm{A} 28+\mathrm{A} 10$ & -1.24 & 1.21 & $-0.004 * * *$ & $-0.007 * * *$ & $0.004 * *$ & 0.097 & $\mathrm{~A} 10+\mathrm{A} 117+\mathrm{A} 33$ & $5.03 * * *$ & $1.55^{*}$ & $0.004 * * *$ & $\overline{0.006^{* * *}}$ & $0.003 * *$ & 0.086 \\
\hline $\mathrm{A} 18+\mathrm{A} 40+\mathrm{A} 10$ & -1.53 & $1.4^{*}$ & $-0.005^{* * *}$ & $-0.005 * *$ & $0.004 * *$ & 0.093 & $\mathrm{~A} 18+\mathrm{A} 80+\mathrm{A} 33$ & $-\overline{3.12 * * *}$ & $1.61^{* *}$ & $\overline{-}-005 * * *$ & $\overline{-}-005 * * *$ & $0.003^{* *}$ & 0.102 \\
\hline $\mathrm{A} 18+\mathrm{A} 43+\mathrm{A} 73$ & $-1.21 *$ & $1.42^{*}$ & $-0.005 * * *$ & $-0.004 * *$ & $-0.002 * *$ & 0.098 & $\mathrm{~A} 18+\mathrm{A} 80+\mathrm{A} 42$ & $-1.18^{*}$ & $1.67 * *$ & $0.006^{* * * *}$ & $-0.003 * *$ & $-0.005 * *$ & 0.102 \\
\hline $\mathrm{A} 18+\mathrm{A} 60+\mathrm{A} 10$ & $-3.04 * * *$ & $1.56^{*}$ & $-0.004 * *$ & $-0.004 * * *$ & $0.003 * *$ & 0.093 & $\mathrm{~A} 18+\mathrm{A} 80+\mathrm{A} 43$ & -1.24 & $1.68^{* *}$ & $0.005 * * *$ & $0.004 * * *$ & $0.004 * * *$ & 0.105 \\
\hline $\mathrm{A} 18+\mathrm{A} 60+\mathrm{A} 73$ & $-1.48^{* *}$ & $1.48^{*}$ & $-0.004 * * *$ & $-0.003 * *$ & $-0.002 * *$ & 0.095 & $\mathrm{~A} 18+\mathrm{A} 80+\mathrm{A} 60$ & $-1.59 * *$ & $1.75^{* *}$ & $\overline{0.005 * * *}$ & $\overline{0.004 * * *}$ & $-0.003 * *$ & 0.099 \\
\hline $\mathrm{A} 18+\mathrm{A} 62+\mathrm{A} 10$ & $-3.33 * * *$ & $1.49 *$ & $-0.004 * * *$ & $-0.003 * *$ & $0.004 * *$ & 0.089 & $\mathrm{~A} 18+\mathrm{A} 80+\mathrm{A} 99$ & $-1.86 * * *$ & $1.61 * *$ & $\overline{0} .005 * * *$ & $-0.003 * *$ & $-0.003 * *$ & 0.098 \\
\hline $\mathrm{A} 18+\mathrm{A} 73+\mathrm{A} 43$ & $-1.21^{*}$ & $1.42 *$ & $-0.005^{* * *}$ & $-0.002 * *$ & $-0.004 * *$ & 0.098 & $\mathrm{~A} 18+\mathrm{A} 87+\mathrm{A} 33$ & $-2.2 * * *$ & $1.29 *$ & $-0.004 * *$ & $\overline{0.006 * * *}$ & $0.003 * *$ & 0.097 \\
\hline $\mathrm{A} 18+\mathrm{A} 102+\mathrm{A} 43$ & -1.26 & $1.53 *$ & $-0.004 * * *$ & $-0.003 * *$ & $-0.003 * *$ & 0.096 & $\mathrm{~A} 18+\mathrm{A} 87+\mathrm{A} 43$ & -0.94 & $1.49 * *$ & $\overline{0} .004 * * *$ & $-0.004 * *$ & $-0.003 * *$ & 0.096 \\
\hline $\mathrm{A} 28+\mathrm{A} 31+\mathrm{A} 43$ & $-2.94 * *$ & $1.68 *$ & $-0.005 * *$ & $0.004^{* *}$ & $-0.004 * *$ & 0.083 & $\mathrm{~A} 28+\mathrm{A} 33+\mathrm{A} 10$ & $3.34 * * *$ & $1.28 *$ & $\overline{0.008 * * *}$ & $0.003 * *$ & $0.006 * * *$ & 0.086 \\
\hline $\mathrm{A} 28+\mathrm{A} 31+\mathrm{A} 62$ & $-2.99 * *$ & $1.56^{*}$ & $-0.006 * * *$ & $0.005 * *$ & $-0.003 * *$ & 0.083 & $\mathrm{~A} 28+\mathrm{A} 33+\mathrm{A} 74$ & $-2.32 * *$ & $1.49 * *$ & $-0.005^{* *}$ & $0.005 * * *$ & $-0.004 * *$ & 0.075 \\
\hline $\mathrm{A} 28+\mathrm{A} 43+\mathrm{A} 31$ & $-2.94 * *$ & $1.68^{*}$ & $-0.005 * *$ & $-0.004 * *$ & $0.004 * *$ & 0.083 & $\mathrm{~A} 28+\mathrm{A} 33+\mathrm{A} 102$ & $-2.3^{*}$ & $1.34 *$ & $-0.005 * *$ & $0.004 * * *$ & $\overline{0.005 * * *}$ & 0.079 \\
\hline $\mathrm{A} 28+\mathrm{A} 62+\mathrm{A} 31$ & $-2.99 * *$ & $1.56^{*}$ & $-0.006^{* * * *}$ & $-0.003 * *$ & $0.005 * *$ & 0.083 & $\mathrm{~A} 28+\mathrm{A} 33+\mathrm{A} 117$ & -1.88 & $1.37 *$ & $-0.005^{* *}$ & $0.003 * * *$ & $0.006^{* * * *}$ & 0.079 \\
\hline $\mathrm{A} 31+\mathrm{A} 40+\mathrm{A} 62$ & $-3.97 * * *$ & $1.82 * *$ & $0.005 * *$ & $-0.004 * *$ & $-0.004 * *$ & 0.076 & $\mathrm{~A} 31+\mathrm{A} 80+\mathrm{A} 43$ & $-\overline{4} .37 * * *$ & $2.04 * *$ & $0.004 * *$ & $\overline{0.004 * * *}$ & $\overline{0.005 * * *}$ & 0.1 \\
\hline $\mathrm{A} 31+\mathrm{A} 60+\mathrm{A} 62$ & $-4.38 * * *$ & $1.78 * *$ & $0.004 * *$ & $-0.005 * * *$ & $-0.003 * *$ & 0.088 & $\mathrm{~A} 31+\mathrm{A} 80+\mathrm{A} 60$ & $-7.73^{* * * *}$ & $2.06 * * *$ & $0.005 * *$ & $0.004^{* * *}$ & $\overline{0.004 * * *}$ & 0.097 \\
\hline $\mathrm{A} 31+\mathrm{A} 62+\mathrm{A} 28$ & $-2.99 * *$ & $1.56^{*}$ & $0.005 * *$ & $-0.003 * *$ & $-0.006 * * *$ & 0.083 & $\mathrm{~A} 32+\mathrm{A} 33+\mathrm{A} 40$ & -1.6 & $1.53 * *$ & $-0.004 * *$ & $0.004 * * *$ & $0.007^{* * * *}$ & 0.076 \\
\hline $\mathrm{A} 31+\mathrm{A} 62+\mathrm{A} 40$ & $-3.97 * * *$ & $1.82 * *$ & $0.005 * *$ & $-0.004 * *$ & $-0.004 * *$ & 0.076 & $\mathrm{~A} 32+\mathrm{A} 33+\mathrm{A} 41$ & $3.01 * * *$ & $1.63 * *$ & $-0.004 * *$ & $0.003 * *$ & $0.005^{* * *}$ & 0.072 \\
\hline $\mathrm{A} 31+\mathrm{A} 62+\mathrm{A} 43$ & $-4.42 * * *$ & $1.84 *$ & $0.004 * *$ & $-0.003 * *$ & $-0.004 * *$ & 0.082 & $\mathrm{~A} 32+\mathrm{A} 33+\mathrm{A} 43$ & $-\overline{2.61 * * *}$ & $1.64 * *$ & $-0.004 * *$ & $0.003 * *$ & $0.005^{* * *}$ & 0.082 \\
\hline $\mathrm{A} 43+\mathrm{A} 82+\mathrm{A} 10$ & $-3.32 * * *$ & $1.85^{*}$ & $-0.005^{* * *}$ & $-0.003 * *$ & $0.004 * *$ & 0.089 & $\mathrm{~A} 32+\mathrm{A} 33+\mathrm{A} 60$ & $2.82 * * *$ & $1.64 * *$ & $-0.005^{* *}$ & $0.003^{* *}$ & $0.005 * * *$ & 0.079 \\
\hline $\mathrm{A} 43+\mathrm{A} 82+\mathrm{A} 18$ & -1.15 & $1.66^{*}$ & $-0.004 * * *$ & $-0.003 * *$ & $-0.005 * * *$ & 0.095 & $\mathrm{~A} 32+\mathrm{A} 33+\mathrm{A} 72$ & $3.13 * * *$ & $1.74 * *$ & $-0.005^{* *}$ & $0.004 * * *$ & $-0.005 * *$ & 0.073 \\
\hline $\mathrm{A} 60+\mathrm{A} 62+\mathrm{A} 10$ & $-3.31 * * *$ & $1.64 *$ & $-0.004 * * *$ & $-0.003 * *$ & $0.004 * *$ & 0.091 & $\mathrm{~A} 32+\mathrm{A} 33+\mathrm{A} 74$ & $3.51 * * *$ & $1.63^{* *}$ & $-0.004 * *$ & $0.005 * * *$ & $-0.004 * *$ & 0.076 \\
\hline $\mathrm{A} 60+\mathrm{A} 62+\mathrm{A} 31$ & $-4.38 * * *$ & $1.78^{* * *}$ & $-0.005 * * *$ & $-0.003^{* *}$ & $0.004 * *$ & 0.088 & $\mathrm{~A} 32+\mathrm{A} 33+\mathrm{A} 77$ & $2.95^{* * * *}$ & $1.53^{* *}$ & $-0.005^{* *}$ & $0.003 * *$ & $-0.004 * *$ & 0.072 \\
\hline $\mathrm{A} 60+\mathrm{A} 73+\mathrm{A} 18$ & $-1.48^{* *}$ & $1.48^{*}$ & $-0.003^{* *}$ & $-0.002 * *$ & $-0.004 * * *$ & 0.095 & $\mathrm{~A} 33+\mathrm{A} 41+\mathrm{A} 40$ & $-1.92 *$ & $1.6^{* *}$ & $0.004 * * *$ & $-0.004 * *$ & $-0.006^{* *}$ & 0.074 \\
\hline $\mathrm{A} 10+\mathrm{A} 28+\mathrm{A} 72$ & $-2.3 * *$ & $2.13^{* *}$ & $0.004 * *$ & $-0.005 * *$ & $-0.004 * *$ & 0.063 & $\mathrm{~A} 33+\mathrm{A} 41+\mathrm{A} 74$ & $3.14 * * *$ & $1.58^{* *}$ & $0.005 * * *$ & $0.005^{* * *}$ & $-0.004 * *$ & 0.081 \\
\hline $\mathrm{A} 18+\mathrm{A} 72+\mathrm{A} 73$ & $-1.74 * *$ & $1.98^{* * *}$ & $-0.004 * *$ & $-0.004 * *$ & $-0.002 * *$ & 0.074 & $\mathrm{~A} 33+\mathrm{A} 41+\mathrm{A} 80$ & $-\overline{3.48 * * *}$ & $1.77 * *$ & $0.004 * * *$ & $-0.004 * *$ & $\overline{0.005 * * *}$ & 0.094 \\
\hline $\mathrm{A} 18+\mathrm{A} 73+\mathrm{A} 74$ & $-1.77 *$ & $1.91 * * *$ & $-0.004 * * *$ & $-0.003 * *$ & $-0.003^{* *}$ & 0.075 & $\mathrm{~A} 33+\mathrm{A} 41+\mathrm{A} 117$ & $-3.1 * * *$ & $1.58^{*}$ & $0.003 * *$ & $-0.004 * *$ & $-0.006^{* *}$ & 0.078 \\
\hline
\end{tabular}




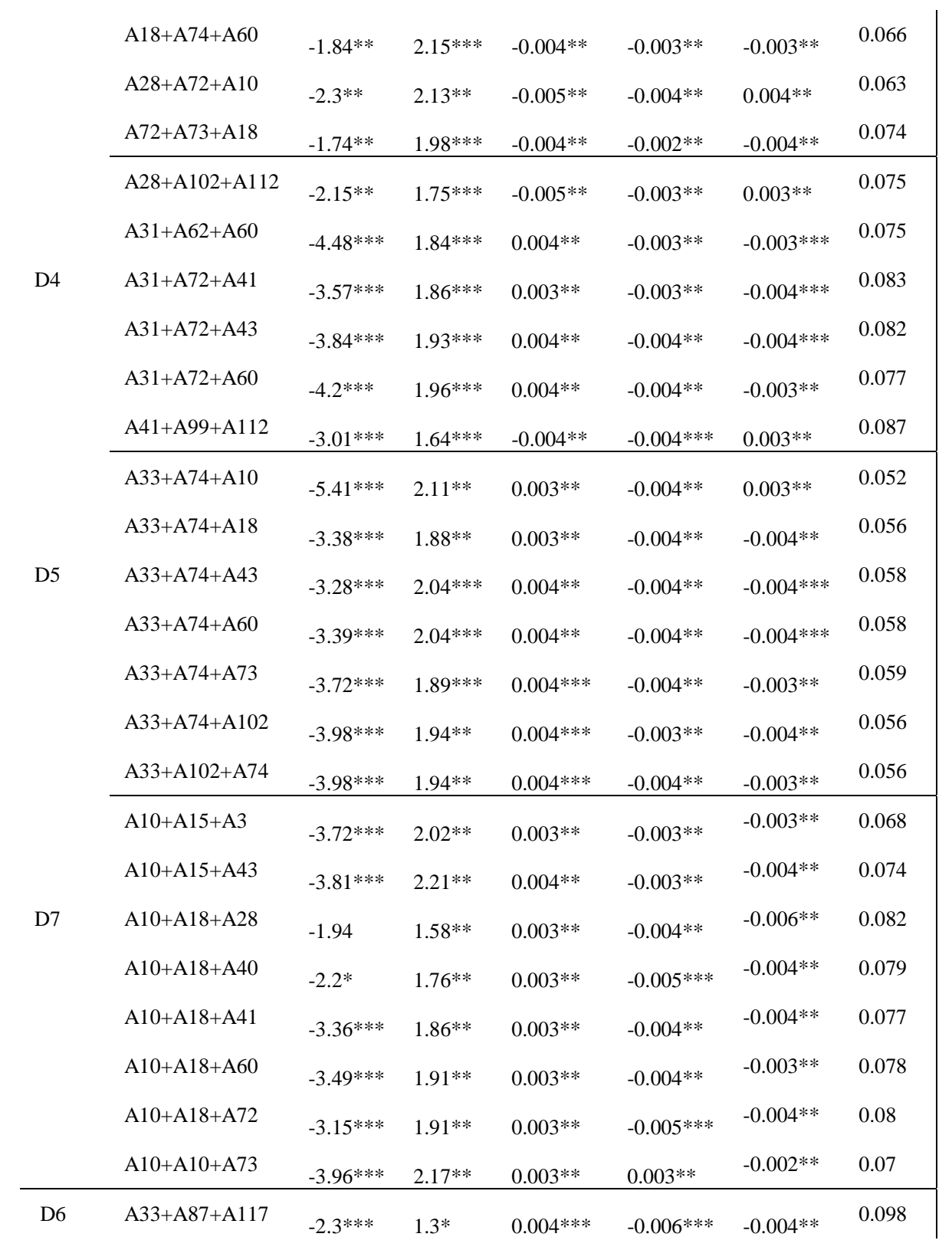

\begin{tabular}{|c|c|c|c|c|c|c|}
\hline $\mathrm{A} 33+\mathrm{A} 74+\mathrm{A} 10$ & $5.76^{* * *}$ & $1.64 * *$ & $0.005 * * *$ & $0.004^{* * * *}$ & $0.005 * * *$ & 0.085 \\
\hline $\mathrm{A} 33+\mathrm{A} 74+\mathrm{A} 18$ & $-\overline{2.73 * * *}$ & $1.37 * *$ & $0.004 * * *$ & $-\overline{0.005 * * *}$ & $-\overline{0.006 * * *}$ & 0.092 \\
\hline $\mathrm{A} 33+\mathrm{A} 74+\mathrm{A} 28$ & $-2.32 * *$ & $1.49 * *$ & $0.005 * * *$ & $-0.004 * *$ & $-0.005 * *$ & 0.075 \\
\hline $\mathrm{A} 33+\mathrm{A} 74+\mathrm{A} 31$ & $6.76 * * *$ & $1.86^{* *}$ & $0.005^{* * * *}$ & $0.005^{* * *} *$ & $0.005^{* *}$ & 0.077 \\
\hline $\mathrm{A} 33+\mathrm{A} 74+\mathrm{A} 41$ & $-14 * * *$ & $1.58 * *$ & $0.005 * * *$ & $-0.004 * *$ & $-\overline{0.005 * * *}$ & 0.081 \\
\hline $\mathrm{A} 33+\mathrm{A} 74+\mathrm{A} 42$ & $-\overline{2.88 * * *}$ & $1.66^{* *}$ & $0.005^{* * * *}$ & $-0.004 * *$ & $\overline{-}-006 * * *$ & 0.089 \\
\hline $\mathrm{A} 33+\mathrm{A} 74+\mathrm{A} 43$ & $-\overline{2.64 * * *}$ & $1.56^{* *}$ & $0.005 * * *$ & $\begin{array}{l}- \\
0.005 * * *\end{array}$ & $-\overline{0.006 * * *}$ & 0.094 \\
\hline $\mathrm{A} 33+\mathrm{A} 74+\mathrm{A} 60$ & $-\overline{2.95 * * *}$ & $1.58 * *$ & $0.005 * * *$ & $-\overline{0.005 * * *}$ & $-\overline{0.005 * * *}$ & 0.089 \\
\hline $\mathrm{A} 33+\mathrm{A} 74+\mathrm{A} 73$ & $3.66 * * *$ & $1.51 * *$ & $0.006 * * *$ & $-\overline{0.005 * * *}$ & $-\overline{0.003 * * *}$ & 0.082 \\
\hline $\mathrm{A} 33+\mathrm{A} 74+\mathrm{A} 77$ & $-\overline{2.99 * * *}$ & $1.43 * *$ & $0.005 * * *$ & $\overline{-}-005 * * *$ & $-0.004 * *$ & 0.083 \\
\hline $\mathrm{A} 33+\mathrm{A} 74+\mathrm{A} 87$ & $-2.22 * * *$ & $1.24 *$ & $0.006 * * *$ & $-0.004 * *$ & $\overline{-}-007 * * *$ & 0.106 \\
\hline $\mathrm{A} 33+\mathrm{A} 74+\mathrm{A} 99$ & $-\overline{3.05 * * *}$ & 1.22 & $0.005 * * *$ & $-0.004 * *$ & $\overline{-}-006 * * *$ & 0.099 \\
\hline $\mathrm{A} 33+\mathrm{A} 74+\mathrm{A} 102$ & $-3.7 * * *$ & $1.44 * *$ & $0.006 * * *$ & $-0.004 * *$ & $\overline{0.005 * * *}$ & 0.088 \\
\hline $\mathrm{A} 33+\mathrm{A} 74+\mathrm{A} 117$ & $3.16 * * *$ & $1.47 *$ & $0.005 * * *$ & $-0.004 * *$ & $\overline{0.006 * * *}$ & 0.088 \\
\hline $\mathrm{A} 33+\mathrm{A} 80+\mathrm{A} 10$ & $-\overline{5.42 * * *}$ & $1.82 * *$ & $0.003 * * *$ & $-\overline{0.005 * * *}$ & $0.004 * *$ & 0.097 \\
\hline $\mathrm{A} 33+\mathrm{A} 80+\mathrm{A} 18$ & $3.12 * * *$ & $1.61 * *$ & $0.003 * *$ & $0.005 * * *$ & $0.005 * * *$ & 0.102 \\
\hline $\mathrm{A} 33+\mathrm{A} 80+\mathrm{A} 41$ & $-\overline{3.48 * * *}$ & $1.77 * *$ & $0.004 * * *$ & $-\overline{0.005 * * *}$ & $-0.004 * *$ & 0.094 \\
\hline $\mathrm{A} 33+\mathrm{A} 80+\mathrm{A} 42$ & $-\overline{3.37 * * *}$ & $1.85 * *$ & $0.004 * * *$ & $\overline{-}-004 * * *$ & -0.00 & 0.096 \\
\hline $\mathrm{A} 33+\mathrm{A} 80+\mathrm{A} 43$ & $\overline{3.01 * * *}$ & $1.76 * *$ & $0.003 * * *$ & $\overline{-}-005 * * *$ & $\overline{-} .005^{* * *}$ & 0.105 \\
\hline $\mathrm{A} 33+\mathrm{A} 80+\mathrm{A} 60$ & $-\overline{3.22 * * *}$ & $1.77 * *$ & $0.004 * * *$ & $\overline{-}-005^{* * *}$ & $\overline{-}-004 * * *$ & 0.102 \\
\hline $\mathrm{A} 33+\mathrm{A} 80+\mathrm{A} 87$ & $2.91 * * *$ & $1.54 * *$ & $0.004 * * *$ & -0.004 & $-0.005 * *$ & 0.105 \\
\hline A33+A80+A99 & $-\overline{3.51 * * *}$ & $1.53^{*}$ & $0.004 * * *$ & $\overline{-}-004 * * *$ & $\overline{-}-004 * * *$ & 0.102 \\
\hline $\mathrm{A} 33+\mathrm{A} 80+\mathrm{A} 102$ & $-3.7 * * *$ & $1.6^{* *}$ & $0.005 * * *$ & $0.005^{* * *}$ & $\overline{-}-004 * * *$ & 0.103 \\
\hline $\mathrm{A} 33+\mathrm{A} 80+\mathrm{A} 117$ & $3.37 * * *$ & $1.66^{*}$ & $0.004 * * *$ & $\overline{0.005 * * *}$ & $-0.005 * *$ & 0.1 \\
\hline $\mathrm{A} 33+\mathrm{A} 82+\mathrm{A} 10$ & $6.36 * * *$ & $1.87 * *$ & $0.003^{* *}$ & $-0.003 * *$ & $0.005 * * *$ & .078 \\
\hline
\end{tabular}




\begin{tabular}{|c|c|c|c|c|c|c|c|c|c|c|c|c|c|}
\hline $\mathrm{A} 33+\mathrm{A} 102+\mathrm{A} 10$ & $-5.57 * * *$ & $1.51 *$ & $0.004 * * *$ & $-0.005^{* * *}$ & $0.005^{* * *}$ & 0.086 & $\mathrm{~A} 33+\mathrm{A} 82+\mathrm{A} 28$ & -1.95 & $1.53^{* *}$ & $0.004 * * *$ & $-0.003 * *$ & $-\overline{0.007 * * *}$ & 0.076 \\
\hline $\mathrm{A} 33+\mathrm{A} 102+\mathrm{A} 18$ & $-3.2 * * *$ & $1.39 *$ & $0.003 * *$ & $-0.004 * * *$ & $-0.005 * * *$ & 0.085 & $\mathrm{~A} 33+\mathrm{A} 82+\mathrm{A} 41$ & $-3.5 * * *$ & $1.77 * *$ & $0.004 * * *$ & $-0.003 * *$ & $0.006^{* * *}$ & 0.076 \\
\hline $\mathrm{A} 33+\mathrm{A} 102+\mathrm{A} 28$ & $-2.3 *$ & $1.34 *$ & $0.004 * * *$ & $-0.005^{* * * *}$ & $-0.005^{* *}$ & 0.079 & $\mathrm{~A} 33+\mathrm{A} 82+\mathrm{A} 43$ & $2.99 * * *$ & $1.77 * *$ & $0.004 * * *$ & $-0.004 * *$ & $\overline{0.006 * * *}$ & 0.091 \\
\hline $\mathrm{A} 33+\mathrm{A} 102+\mathrm{A} 42$ & $-3.2 * * *$ & $1.61 * *$ & $0.004 * * *$ & $-0.004 * *$ & $-0.005 * * *$ & 0.085 & $\mathrm{~A} 33+\mathrm{A} 82+\mathrm{A} 60$ & $3.39 * * *$ & $1.81 * *$ & $0.004 * * *$ & $-0.004 * *$ & $0.006^{* * *}$ & 0.084 \\
\hline $\mathrm{A} 33+\mathrm{A} 102+\mathrm{A} 43$ & $-3.12 * * *$ & $1.54^{*}$ & $0.004 * * *$ & $-0.004 * * *$ & $-0.005 * * *$ & 0.088 & $\mathrm{~A} 33+\mathrm{A} 82+\mathrm{A} 77$ & $-3.5^{* * *}$ & $1.66 * *$ & $0.003^{* *}$ & $-0.003 * *$ & $0.005 * * *$ & 0.076 \\
\hline $\mathrm{A} 33+\mathrm{A} 102+\mathrm{A} 60$ & $-3.6 * * *$ & $1.61 * *$ & $0.004 * * *$ & $-0.004 * *$ & $-0.004 * *$ & 0.08 & $\mathrm{~A} 33+\mathrm{A} 87+\mathrm{A} 10$ & $-\overline{3.98 * * *}$ & $1.36^{*}$ & $0.003 * * *$ & $0.007 * * *$ & $0.004 * * *$ & 0.1 \\
\hline $\mathrm{A} 33+\mathrm{A} 102+\mathrm{A} 74$ & $-3.7 * * *$ & $1.44 * *$ & $0.006 * * *$ & $-0.005 * * *$ & $-0.004 * *$ & 0.088 & $\mathrm{~A} 33+\mathrm{A} 87+\mathrm{A} 18$ & $-2.2 * * *$ & $1.29 *$ & $0.003 * *$ & $0.006^{* * * *}$ & $-0.004 * *$ & 0.097 \\
\hline $\mathrm{A} 33+\mathrm{A} 102+\mathrm{A} 80$ & $-3.7 * * *$ & $1.6^{* * *}$ & $0.005 * * *$ & $-0.004 * * *$ & $-0.005^{* * *}$ & 0.103 & $\mathrm{~A} 33+\mathrm{A} 87+\mathrm{A} 40$ & -1.17 & $1.28 *$ & $0.004 * * *$ & $0.007 * * *$ & $-0.005 * *$ & 0.098 \\
\hline $\mathrm{A} 33+\mathrm{A} 102+\mathrm{A} 87$ & $-2.69 * * *$ & $1.3^{*}$ & $0.004 * * *$ & $-0.003 * *$ & $-0.006 * * *$ & 0.097 & $\mathrm{~A} 33+\mathrm{A} 87+\mathrm{A} 43$ & $-\overline{2} 23 * * *$ & $1.43 *$ & $0.003 * * *$ & $0.006^{* * * *}$ & $-0.003 * *$ & 0.098 \\
\hline $\mathrm{A} 33+\mathrm{A} 102+\mathrm{A} 117$ & $-3.52 * * *$ & $1.47^{*}$ & $0.004 * * *$ & $-0.004 * *$ & $-0.005^{* *}$ & 0.083 & $\mathrm{~A} 33+\mathrm{A} 87+\mathrm{A} 60$ & $-2.2^{* * *}$ & $1.39 * *$ & $0.003 * * *$ & $0.007 * * *$ & $-0.003 * *$ & 0.098 \\
\hline $\mathrm{A} 80+\mathrm{A} 87+\mathrm{A} 33$ & $-2.91 * * *$ & $1.54 * *$ & $-0.004 * *$ & $-0.005 * *$ & $0.004 * * *$ & 0.105 & $\mathrm{~A} 33+\mathrm{A} 87+\mathrm{A} 74$ & $-2.22 * * *$ & $1.24 *$ & $0.006 * * *$ & $\overline{0.007 * * *}$ & $-0.004 * *$ & 0.106 \\
\hline A $80+A 99+A 33$ & $-3.51 * * *$ & $1.53^{*}$ & $-0.004 * * *$ & $-0.004 * * *$ & $0.004 * * *$ & 0.102 & $\mathrm{~A} 33+\mathrm{A} 87+\mathrm{A} 80$ & $2.91 * * *$ & $1.54 * *$ & $0.004 * * *$ & $-0.005^{* *}$ & $-0.004 * *$ & 0.105 \\
\hline A80+A99+A43 & $-1.79 * * *$ & $1.84 * *$ & $-0.003 * * *$ & $-0.003 * *$ & $-0.004 * *$ & 0.096 & A33+A87+A99 & $-\overline{2.56 * * *}$ & $1.23^{*}$ & $0.003^{* * * *}$ & $\overline{0}-005^{* * *}$ & $-0.004 * *$ & 0.1 \\
\hline & & & & & & & $\mathrm{A} 33+\mathrm{A} 87+\mathrm{A} 102$ & $-\overline{2.69 * * *}$ & $1.3 *$ & $0.004 * * *$ & $\overline{0} .006 * * *$ & $-0.003 * *$ & 0.097 \\
\hline
\end{tabular}

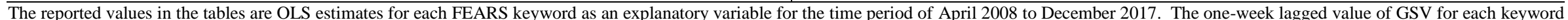

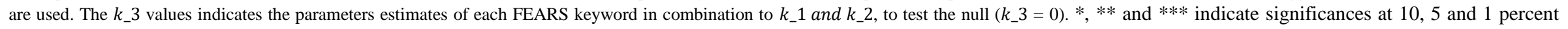
respectively level of significance. 
INVESTMENT ANALYSTS JOURNAL

https://doi.org/10.1080/10293523.2019.1643968 


\section{A5: list of the primitive Sentiment keywords consists of FEARS sentiment index for Islamic Stock market}

\begin{tabular}{|c|c|}
\hline $\begin{array}{l}\text { Fears } \\
\text { Index }\end{array}$ & Primitive Sentiment Keywords \\
\hline FEARS15 & A3 A68 A10 A18 A28 A32 A33 A62 A71 A72 A73 A77 A87 A99 A117 \\
\hline FEARS30 & $\begin{array}{l}\text { A56 A88 A55 A34 A36 A57 A54 A83 A108 A30 A52 A53 A22 A5 A113 A65 A4 A109 A18 A17 A45 A94 A35 A106 A100 A31 A112 A101 } \\
\text { A78 A12 }\end{array}$ \\
\hline FEARS1 & 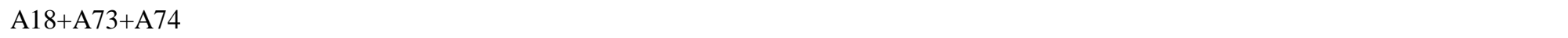 \\
\hline FEARS2 & $\mathrm{A} 18+\mathrm{A} 43+\mathrm{A} 73$ \\
\hline FEARS3 & $\mathrm{A} 18+\mathrm{A} 73+\mathrm{A} 74$ \\
\hline FEARS4 & $\mathrm{A} 31+\mathrm{A} 72+\mathrm{A} 41$ \\
\hline FEARS5 & $\mathrm{A} 33+\mathrm{A} 74+\mathrm{A} 60$ \\
\hline FEARS6 & $\mathrm{A} 33+\mathrm{A} 74+\mathrm{A} 87$ \\
\hline FEARS7 & $\mathrm{A} 10+\mathrm{A} 18+\mathrm{A} 28$ \\
\hline FEARSgc1 & A3 A6 A7 A8 A10 A15 A18 A28 A31 A32 A33 A37 A41 A53 A62 A71 A72 A73 A74 A77 A87 A88 A99 A102 A112 A117 \\
\hline FEARSgc2 & $\begin{array}{l}\text { A3 A6 A7 A8 A10 A14 A15 A18 A26 A28 A31 A32 A33 A37 A38 A40 A41 A42 A43 A53 A58 A60 A62 A71 A72 A73 A74 A77 A80 A82 } \\
\text { A87 A99 A102 A112 }\end{array}$ \\
\hline FEARSgc3 & A3 A6 A7 A8 A10 A15 A18 A28 A32 A33 A37 A53 A62 A71 A72 A73 A77 A87 A88 A99 A112 A117 \\
\hline FEARSgc4 & A3 A6 A8 A10 A15 A18 A26 A28 A31 A32 A33 A38 A41 A42 A62 A65 A73 A74 A77 A87 A99 A102 A117 \\
\hline FEARSgc5 & A3 A5 A6 A8 A10 A14 A15 A18 A28 A31 A32 A33 A38 A53 A62 A71 A72 A73 A77 A80 A87 A88 A99 A112 A117 \\
\hline FEARSgc6 & A3 A5 A6 A7 A8 A10 A18 A28 A31 A32 A33 A38 A41 A53 A62 A65 A71 A72 A73 A74 A77 A80 A82 A87 A88 A99 A112 A117 \\
\hline FEARSgc7 & A3 A6 A8 A10 A18 A28 A31 A32 A33 A38 A53 A62 A71 A72 A73 A77 A87 A88 A99 A112 A117 \\
\hline
\end{tabular}




\section{A6: FEARS15 and FEEARS30 and Islamic stocks unconditional and conditional volatility (January 2010-December 2013)}

\begin{tabular}{|c|c|c|c|c|c|c|c|c|c|c|c|c|c|c|}
\hline VAR & D1D & D2D & D3D & D4D & D5D & D6D & D7D & LAH1 & LAH2 & LAH3 & LAH4 & LAH5 & LAH6 & LAH7 \\
\hline FEARS15 & $-0.000932 *$ & $-0.00111^{* *}$ & $-0.000863^{*}$ & $-0.00146^{* *}$ & $-0.000923^{* *}$ & $-0.000989 * *$ & $-0.000902 * *$ & -0.0324 & -0.0842 & -0.0324 & -0.199 & 0.0197 & -0.131 & -0.0544 \\
\hline R-squared & 0.018 & 0.02 & 0.017 & 0.028 & 0.02 & 0.024 & 0.019 & 0 & 0.001 & 0 & 0.006 & 0 & 0.002 & 0 \\
\hline FEARS15L1 & $-0.000986 * *$ & $-0.00115^{* *}$ & $-0.000911^{* *}$ & $-0.00171 * * *$ & $-0.000948 * *$ & $-0.00100 * *$ & $-0.000938 * *$ & -0.114 & -0.149 & -0.114 & $-0.452 * *$ & -0.196 & -0.242 & -0.218 \\
\hline R-squared & 0.02 & 0.02 & 0.019 & 0.038 & 0.02 & 0.023 & 0.02 & 0.001 & 0.002 & 0.001 & 0.029 & 0.004 & 0.007 & 0.006 \\
\hline FEARS15L2 & $-0.000854 *$ & $-0.000964 *$ & $-0.000799 *$ & $-0.00132 * *$ & -0.000761 & $-0.000756^{*}$ & $-0.000807 *$ & -0.203 & -0.064 & -0.203 & $-0.352 *$ & -0.074 & -0.287 & -0.252 \\
\hline R-squared & 0.015 & 0.014 & 0.014 & 0.022 & 0.013 & 0.013 & 0.014 & 0.004 & 0 & 0.004 & 0.017 & 0.001 & 0.009 & 0.008 \\
\hline FEARS15L3 & -0.000753 & -0.000875 & -0.000695 & $-0.00141 * *$ & -0.00073 & $-0.000849 *$ & -0.000664 & -0.0239 & 0.0551 & -0.0239 & -0.0464 & -0.19 & -0.0624 & -0.157 \\
\hline R-squared & 0.012 & 0.012 & 0.011 & 0.025 & 0.012 & 0.017 & 0.01 & 0 & 0 & 0 & 0 & 0.004 & 0 & 0.003 \\
\hline FEARS15L4 & $-0.00122 * *$ & $-0.00133 * *$ & $-0.00116^{* *}$ & $-0.00180 * * *$ & $-0.00117 * *$ & $-0.00131 * * *$ & $-0.00116^{* *}$ & -0.0982 & -0.0713 & -0.0982 & $-0.347 *$ & -0.0404 & -0.0829 & -0.179 \\
\hline R-squared & 0.031 & 0.027 & 0.03 & 0.041 & 0.031 & 0.04 & 0.03 & 0.001 & 0.001 & 0.001 & 0.017 & 0 & 0.001 & 0.004 \\
\hline FEARS30 & 0.000167 & 0.000173 & 0.000141 & 0.000595 & 0.000123 & 0.000176 & $9.15 \mathrm{E}-05$ & -0.101 & -0.106 & -0.101 & 0.112 & -0.108 & 0.0408 & -0.0218 \\
\hline R-squared & 0.001 & 0.001 & 0.001 & 0.008 & 0.001 & 0.001 & 0 & 0.002 & 0.002 & 0.002 & 0.003 & 0.002 & 0 & 0 \\
\hline FEARS30L1 & 0.000176 & 0.000269 & 0.000136 & 0.000588 & 0.000122 & 0.000218 & $8.65 \mathrm{E}-05$ & -0.132 & -0.138 & -0.132 & 0.0779 & -0.162 & -0.0837 & -0.112 \\
\hline R-squared & 0.001 & 0.002 & 0.001 & 0.008 & 0.001 & 0.002 & 0 & 0.003 & 0.004 & 0.003 & 0.002 & 0.005 & 0.001 & 0.003 \\
\hline FEARS30L2 & 0.000387 & 0.000426 & 0.000349 & $0.000777 *$ & 0.000316 & 0.000407 & 0.000296 & -0.14 & -0.0845 & -0.14 & 0.0382 & -0.124 & 0.0163 & -0.0812 \\
\hline R-squared & 0.005 & 0.005 & 0.005 & 0.014 & 0.004 & 0.007 & 0.003 & 0.004 & 0.001 & 0.004 & 0 & 0.003 & 0 & 0.001 \\
\hline FEARS30L3 & 0.000409 & 0.000424 & 0.00037 & 0.000716 & 0.000342 & 0.000454 & 0.00033 & -0.0879 & -0.0606 & -0.0879 & 0.0979 & -0.142 & 0.0266 & -0.0647 \\
\hline R-squared & 0.006 & 0.005 & 0.005 & 0.012 & 0.005 & 0.008 & 0.004 & 0.001 & 0.001 & 0.001 & 0.002 & 0.004 & 0 & 0.001 \\
\hline FEARS30L4 & 0.000383 & 0.000378 & 0.000354 & 0.000582 & 0.000332 & 0.00048 & 0.000312 & -0.0576 & -0.173 & -0.0576 & -0.0241 & -0.113 & -0.00883 & -0.0456 \\
\hline R-squared & 0.005 & 0.004 & 0.005 & 0.008 & 0.004 & 0.009 & 0.004 & 0.001 & 0.006 & 0.001 & 0 & 0.002 & 0 & 0 \\
\hline
\end{tabular}

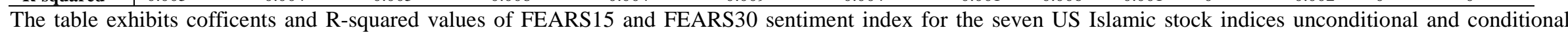

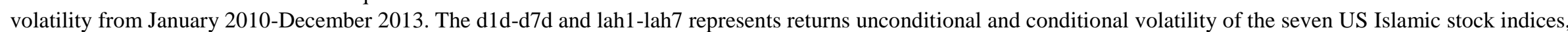

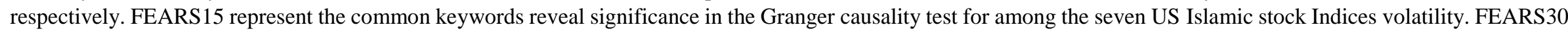
denotes Da et al. (2015) original 30 keywords FEARS index. ***,**, * denote p-values at 1, 5 and 10 percent respectively. 


\section{A7: FEARS15 and FEEARS30 and Islamic stocks unconditional and conditional volatility (January 2014-December 2017)}

\begin{tabular}{|c|c|c|c|c|c|c|c|c|c|c|c|c|c|c|}
\hline VAR & D1D & D2D & D3D & D4D & D5D & D6D & D7D & LAH1 & LAH2 & LAH3 & LAH4 & LAH5 & LAH6 & LAH7 \\
\hline FEARS15 & $-0.00119^{* * *}$ & $-0.000960^{* * *}$ & $-0.00123 * * *$ & $-0.000889 * * *$ & $-0.00138 * * *$ & $-0.00138 * * *$ & $-0.00120^{* * *}$ & $-0.551 * * *$ & $-0.517 * * *$ & $-0.551^{* * *}$ & $-0.334 * *$ & $-0.532 * * *$ & $-0.624 * * *$ & $-0.585^{* * *}$ \\
\hline R-squared & 0.067 & 0.043 & 0.071 & 0.034 & 0.09 & 0.093 & 0.069 & 0.053 & 0.05 & 0.053 & 0.02 & 0.041 & 0.05 & 0.06 \\
\hline FEARS15L1 & $-0.00100^{* * * *}$ & $-0.000794 * *$ & $-0.00105 * * *$ & $-0.000630^{*}$ & $-0.00117 * * *$ & $-0.00117 * * *$ & $-0.00102 * * *$ & $-0.430^{* * * *}$ & $-0.464 * * *$ & $-0.430^{* * * *}$ & -0.252 & $-0.334 *$ & $-0.464 * *$ & $-0.467^{* * *}$ \\
\hline R-squared & 0.048 & 0.029 & 0.052 & 0.017 & 0.066 & 0.068 & 0.05 & 0.033 & 0.041 & 0.033 & 0.012 & 0.017 & 0.028 & 0.039 \\
\hline FEARS15L2 & $-0.00129 * * *$ & $-0.000988 * * *$ & $-0.00134 * * *$ & $-0.000894 * * *$ & $-0.00150^{* * *}$ & $-0.00154 * * *$ & $-0.00132 * * *$ & $-0.614^{* * * *}$ & $-0.328 * *$ & $-0.614 * * *$ & -0.175 & $-0.331^{*}$ & $-0.445^{* *}$ & $-0.496^{* * *}$ \\
\hline R-squared & 0.079 & 0.045 & 0.084 & 0.035 & 0.108 & 0.116 & 0.084 & 0.066 & 0.02 & 0.066 & 0.005 & 0.016 & 0.026 & 0.044 \\
\hline FEARS15L3 & $-0.00155^{* * *}$ & $-0.00132^{* * * *}$ & $-0.00159 * * *$ & $-0.00119 * * *$ & $-0.00168 * * *$ & $-0.00172 * * *$ & $-0.00157^{* * *}$ & $-0.384^{* *}$ & $-0.454 * * *$ & $-0.384 * *$ & -0.214 & $-0.442 * *$ & $-0.373 *$ & $-0.395 * *$ \\
\hline R-squared & 0.115 & 0.081 & 0.119 & 0.062 & 0.135 & 0.147 & 0.12 & 0.026 & 0.039 & 0.026 & 0.008 & 0.029 & 0.018 & 0.028 \\
\hline FEARS15L4 & $-0.00142 * * *$ & $-0.00117^{* * *}$ & $-0.00147 * * *$ & $-0.00107^{* * *}$ & $-0.00159 * * *$ & $-0.00165 * * *$ & $-0.00143 * * *$ & $-0.460^{* * * *}$ & $-0.404 * *$ & $-0.460^{* * * *}$ & -0.115 & $-0.528^{* * *}$ & $-0.612^{* * *}$ & $-0.479 * * *$ \\
\hline R-squared & 0.096 & 0.064 & 0.103 & 0.051 & 0.122 & 0.135 & 0.099 & 0.037 & 0.031 & 0.037 & 0.002 & 0.041 & 0.049 & 0.041 \\
\hline FEARS30 & $0.00129^{* * *}$ & $0.00144 * * *$ & $0.00125 * * *$ & $0.00152^{* * *}$ & $0.00129 * * *$ & $0.00145^{* * *}$ & $0.00127 * * *$ & $0.454 * * *$ & $0.488 * * *$ & $0.454^{* * * *}$ & 0.257 & $0.385^{* *}$ & $0.516^{* * *}$ & $0.507 * * *$ \\
\hline R-squared & 0.083 & 0.101 & 0.078 & 0.107 & 0.085 & 0.11 & 0.081 & 0.038 & 0.047 & 0.038 & 0.013 & 0.023 & 0.036 & 0.048 \\
\hline FEARS30L1 & $0.00103 * * *$ & $0.00116 * * *$ & $0.000988 * * *$ & $0.00129 * * *$ & $0.00107 * * *$ & $0.00120^{* * *}$ & $0.00101 * * *$ & $0.480^{* * *}$ & $0.584 * * *$ & $0.480 * * *$ & $0.335 * *$ & $0.411^{* *}$ & $0.643 * * *$ & $0.486^{* * * *}$ \\
\hline R-squared & 0.051 & 0.063 & 0.047 & 0.074 & 0.055 & 0.072 & 0.05 & 0.042 & 0.068 & 0.042 & 0.021 & 0.026 & 0.056 & 0.044 \\
\hline FEARS30L2 & $0.000709 * *$ & $0.000834 * * *$ & $0.000660 * *$ & $0.00101 * * *$ & $0.000774 * *$ & $0.000900 * * *$ & $0.000688^{* *}$ & $0.526 * * *$ & $0.527 * * *$ & $0.526 * * *$ & $0.374 * *$ & $0.376^{* *}$ & $0.562 * * *$ & $0.491 * * *$ \\
\hline R-squared & 0.024 & 0.033 & 0.021 & 0.045 & 0.029 & 0.04 & 0.023 & 0.05 & 0.054 & 0.05 & 0.026 & 0.021 & 0.042 & 0.044 \\
\hline FEARS30L3 & 0.000405 & 0.000516 & 0.000365 & $0.000724 * *$ & 0.00043 & $0.000568 *$ & 0.000406 & $0.373^{* *}$ & $0.524 * * *$ & $0.373^{* *}$ & 0.263 & 0.28 & $0.496^{* * *}$ & $0.397^{* *}$ \\
\hline R-squared & 0.008 & 0.012 & 0.006 & 0.023 & 0.009 & 0.016 & 0.008 & 0.024 & 0.052 & 0.024 & 0.012 & 0.012 & 0.032 & 0.028 \\
\hline FEARS30L4 & $0.000593 *$ & $0.000606^{*}$ & $0.000585^{*}$ & $0.000791 * *$ & $0.000597^{*}$ & $0.000708 * *$ & $0.000583 *$ & $0.394 * *$ & $0.460 * * *$ & $0.394^{* *}$ & $0.341 * *$ & 0.171 & $0.518 * * *$ & $0.386^{* * *}$ \\
\hline R-squared & 0.017 & 0.017 & 0.016 & 0.027 & 0.017 & 0.025 & 0.016 & 0.027 & 0.04 & 0.027 & 0.021 & 0.004 & 0.035 & 0.026 \\
\hline
\end{tabular}

